Article

\title{
Development of Coumarin-Based Hydroxamates as Histone Deacetylase Inhibitors with Antitumor Activities
}

\author{
Na Zhao ${ }^{1,2,+}$, Feifei Yang ${ }^{2, *,+} \mathbb{D}$, Lina Han ${ }^{2}$, Yuhua $Q u^{2}$, Di Ge $^{2}$ and Hua Zhang ${ }^{2, *(\mathbb{D}}$ \\ 1 School of Chemistry and Chemical Engineering, University of Jinan, Jinan 250022, China; \\ zhaona3702@163.com \\ 2 School of Biological Science and Technology, University of Jinan, Jinan 250022, China; \\ hanln95@163.com (L.H.); 17854175513@163.com (Y.Q.); gedi_blue@126.com (D.G.) \\ * Correspondence: bio_yangff@ujn.edu.cn (F.Y.); bio_zhangh@ujn.edu.cn (H.Z.); \\ Tel.: +86-0531-89736199 (H.Z.) \\ + These authors contributed equally to this work.
}

Received: 28 December 2019; Accepted: 6 February 2020; Published: 7 February 2020

\begin{abstract}
Histone deacetylases (HDACs) have been proved to be promising targets for the treatment of cancer, and five histone deacetylase inhibitors (HDACis) have been approved on the market for the treatment of different lymphomas. In our previous work, we designed a series of novel coumarin-containing hydroxamate HDACis, among which compounds $\mathbf{6}$ and $\mathbf{7}$ displayed promising activities against tumor growth. Based on a molecular docking study, we further developed 26 additional analogues with the aim to improve activity of designed compounds. Several of these new derivatives not only showed excellent HDAC1 inhibitory effects, but also displayed significant growth inhibitory activities against four human cancer cell lines. Representative compounds, 13a and 13c, showed potent anti-proliferative activities against solid tumor cell lines with $\mathrm{IC}_{50}$ values of $0.36-2.91$ $\mu \mathrm{M}$ and low cytotoxicity against Beas-2B and L-02 normal cells. Immunoblot analysis revealed that 13a and 13c dose-dependently increased the acetylation of histone $\mathrm{H} 3$ and $\mathrm{H} 4$. Importantly, the two compounds displayed much better anti-metastatic effects than SAHA against the MDA-MB-231 cell line. Moreover, 13a and 13c arrested MDA-MB-231 cells at G2/M phase and induced MDA-MB-231 cell apoptosis. Finally, the molecular docking study rationalized the high potency of compound 13c.
\end{abstract}

Keywords: coumarin; anti-tumor; HDAC inhibitors; structural modification; anti-proliferative

\section{Introduction}

Cancer is one of the most mortal diseases in the world [1]. In addition to genetic factors, the occurrence of cancer also involves epigenetic modifications including covalent modifications of DNA (methylation and demethylation) and histones [2-6]. Epigenetic regulations achieve reversible modification process through the corresponding enzymes. Histone lysine acetylation level, regulated by histone deacetylases (HDACs) and histone acetyl-transferases (HATs), plays a key role in epigenetic modification [7-11]. Overexpression of HDACs have been found in different cancers [12,13], and histone deacetylase inhibitors (HDACis) have been shown to significantly suppress cell proliferation, angiogenesis and metastasis through multiple mechanisms [14,15].

To date, 18 HDAC isoforms have been found in humans and they can be divided into four classes. Classes I $(1,2,3,8)$, II $(4,5,6,7,9,10)$ and IV (11) HDACs are $\mathrm{Zn}^{2+}$-dependent enzymes, while class III HDACs (SIRT1-7) require NAD ${ }^{+}$for their activities [16-18]. Five HDACis, vorinostat (1, SAHA) [19], bellinostat (2, PXD101) [20], panobinostat (3, LBH589) [21], romidepsin (4, FK228) [22] and chidamide (5, CS055) [23] (Figure 1), have been approved on the market for the treatment of cutaneous T-cell 
lymphoma (CTCL), multiple myeloma (MM) or peripheral T-cell lymphoma (PTCL), and more than 20 other inhibitors are at different stages of clinical trials. However, most HDACis displayed suboptimal results against solid tumors, so it is important to develop novel HDACis to achieve high potency against solid malignancy.<smiles>O=C(CCCCCCC(=O)Nc1ccccc1)NO</smiles>

1 (SAHA)

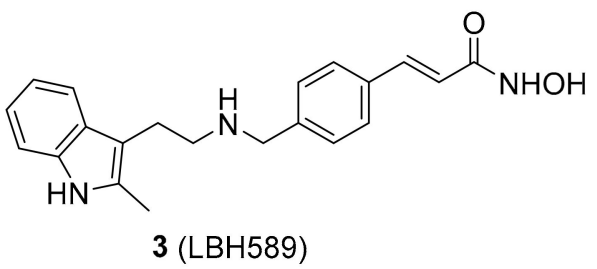<smiles>Nc1ccc(F)cc1NC(=O)c1ccc(CNC(=O)/C=C/c2cccnc2)cc1</smiles><smiles>O=C(/C=C/c1cccc(S(=O)(=O)Nc2ccccc2)c1)NO</smiles>

2 (PXD-101)<smiles>C/C=C1/NC(=O)[C@@H]2CSSC/C=C/C[C@@H](OC2=O)C(=O)N[C@H](C(C)C)C(=O)N[C@H](C(C)C)C(=O)O1</smiles>

4 (FK-228)<smiles></smiles>

Figure 1. Chemical structures of representative histone deacetylase inhibitors (HDACis).

Despite the huge structural diversity, HDACis generally have a common pharmacophore model [24,25]: A zinc binding group (ZBG), a linker and a surface recognition group (CAP group) [26,27]. The CAP region is considered to be a key part for identifying different subtypes of HDACs, which interacts with the surface edge of the enzyme. The linker zone is negatively extended into the hydrophobic cavity of the HDACs [28]. HDACis are generally considered to be a group of promising candidates in anticancer drug discovery.

The coumarin derivatives have various pharmacological properties, such as antitumor, anti-inflammatory, antiviral and antimicrobial activities [29-32]. Previously, we designed and synthesized a series of coumarin-based hydroxamate HDACis, among which, compounds 6 and 7 displayed good inhibition against Class I HDACs [33]. Considering the comparable activities of compounds 6 and 7 and the synthetic convenience, we chose 7 as the initial lead to explore more coumarin-based HDACis with better activities (Figure 2). According to the preliminary docking results of 7 with HDAC1, it was found that the methoxyl group of the CAP region was in the cavity of the rim of the enzyme. Hence we wish to do some modifications on the methoxyl group for the sake of acquiring more valuable inhibitors. Details of the syntheses and biological evaluations of these new HDACis are presented below. 

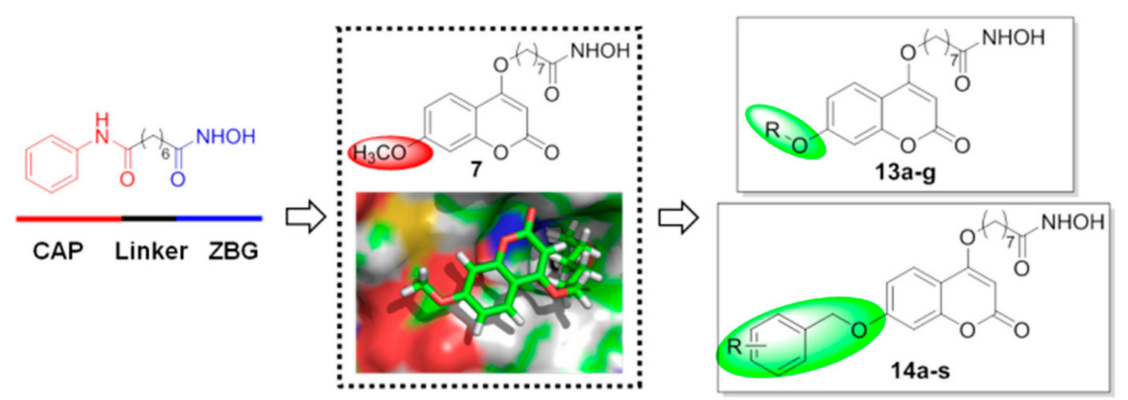

Figure 2. Design strategy and general structures of the target compounds.

\section{Chemistry}

The syntheses of compounds 13a-g and 14a-s are shown in Scheme 1. Compound 8 was first subjected to a ring-closing reaction with diethyl carbonate and sodium hydride at $115{ }^{\circ} \mathrm{C}$ to give product 9, which was subsequently reacted with methyl 8-bromooctanoate in $\mathrm{N}, \mathrm{N}$-dimethylformamid (DMF). The resulting ester was demethylated with $\mathrm{BBr}_{3}(1.0 \mathrm{M}$ in dichloromethane (DCM)) to afford intermediate 11, and $\mathbf{1 1}$ was further reacted with different alkyl bromides and then treated with hydroxylamine hydrochloride to obtain the target compounds 13a-g and 14a-s.

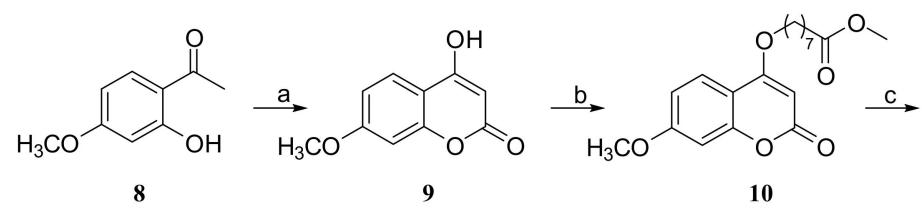

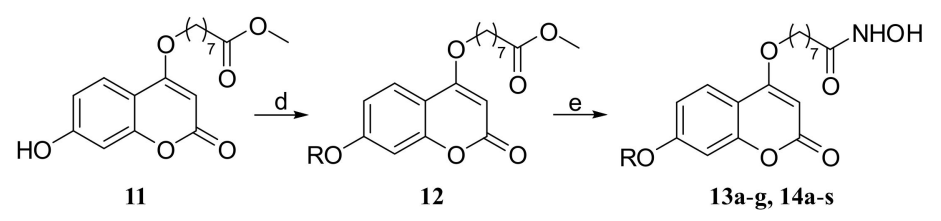

Scheme 1. Synthesis of compounds $\mathbf{1 3 a}-\mathbf{g}$ and 14a-s. Reagents and conditions: (a) $\mathrm{NaH}, \mathrm{CH}_{3} \mathrm{Ph}$, diethyl carbonate, $115^{\circ} \mathrm{C}$, reflux; (b) $\mathrm{Br}\left(\mathrm{CH}_{2}\right)_{7} \mathrm{CO}_{2} \mathrm{CH}_{3}, \mathrm{~K}_{2} \mathrm{CO}_{3}$, DMF; (c) $\mathrm{BBr}$, $\mathrm{DCM}$; (d) $\mathrm{RBr}, \mathrm{K}_{2} \mathrm{CO}_{3}$, DMF; (e) $\mathrm{NH}_{2} \mathrm{OH} \cdot \mathrm{HCl}, \mathrm{KOH}, \mathrm{MeOH}$.

\section{Results and Discussion}

\subsection{HDAC1 Inhibitory Activity of Synthesized Compounds}

The obtained compounds were first tested for their inhibitory activities against HDAC1, and the FDA-approved marketed drug SAHA (1) was used as a positive control, and the obtained half maximal inhibitory concentration $\left(\mathrm{IC}_{50}\right)$ values were shown in Table 1 . In general, all synthesized samples were more active than the control drug (1), and the alkoxy-substituted coumarin derivatives (13-series) showed stronger inhibitory activity than most benzyloxy-substituted ones (14-series).

The 13-series compounds (except 13g) were 16- to 41-fold as active as SAHA (1) and they exhibited a linker-length-dependent inhibition toward HDAC1. The inhibitory activity of the target compounds improved with the elongation of the linker $(\mathbf{1 3 a}-\mathbf{c})$, and $\mathbf{1 3}$ c showed the best activity with an $\mathrm{IC}_{50}$ of $0.30 \mathrm{nM}$. However, the inhibitory activity declined when the alkyl chain continued to extend (13d-e) or was replaced by a branched one (13f). Particularly, when the alkyl chain was linked with a cyclohexyl group (13g), a dramatic decrease of activity was observed. So the proper length and shape of the alkyl chain were very important to the HDAC1 inhibitory activity.

For the 14-series compounds, the simplest 14a showed an $\mathrm{IC}_{50}$ value of $0.96 \mathrm{nM}$, being 12 times more potent than SAHA (1). The inhibitory activities of these benzyloxy derivatives were significantly influenced by different substituents and substituting patterns on the benzyl ring, as analyzed below. 
Among the electron-withdrawing substituents on the mono-substituted benzyloxy fragment (14b-1), a trend of the inhibition was observed for fluoro $>$ nitro $>$ chloro $>$ bromo $>$ trifluoromethyl. When the fluorine was replaced by methyl group (14p-r), it resulted in a decrease of activity. At the same time, the efficacy of compounds was also obviously affected by the substituting position, and those with ortho-substitution $(\mathbf{1 4 b}, \mathbf{1 4 e}, \mathbf{1 4 h}$ and $\mathbf{1 4 p})$ showed the best activity among the three investigated substituting sites (o-, m- and p-positions). Compound $14 \mathrm{e}\left(\mathrm{IC}_{50}=0.75 \mathrm{nM}\right)$ with an ortho-fluoro was the most potent inhibitor among all mono-substituted benzyloxy analogues, and the introduction of one more fluorine at the other ortho-position further improved the activity $\left(\mathbf{1 4 m}, \mathrm{IC}_{50}=0.50 \mathrm{nM}\right)$. However, the HDAC1 inhibitory activities of other disubstituted benzyloxy compounds (14n and 14o) were not better than $\mathbf{1 4 m}$.

Table 1. $\mathrm{IC}_{50}$ values of compounds $13 \mathbf{a}-\mathbf{g}$ and $14 \mathbf{a}-\mathbf{s}$ against HDAC1.

\begin{tabular}{|c|c|c|}
\hline Compounds & $\mathbf{R}$ & $\mathrm{IC}_{50}(\mathrm{nM})$ \\
\hline $13 a$ & & 0.48 \\
\hline $13 b$ & & 0.31 \\
\hline $13 c$ & & 0.30 \\
\hline $13 d$ & & 0.33 \\
\hline $13 e$ & & 0.77 \\
\hline $13 f$ & & 0.60 \\
\hline $13 \mathrm{~g}$ & & 5.01 \\
\hline $14 a$ & & 0.96 \\
\hline $14 b$ & & 1.59 \\
\hline $14 c$ & & 1.97 \\
\hline $14 d$ & & 1.72 \\
\hline $14 \mathrm{e}$ & & 0.75 \\
\hline $14 \mathrm{f}$ & & 0.99 \\
\hline $14 \mathrm{~g}$ & & 0.88 \\
\hline $14 \mathrm{~h}$ & & 2.40 \\
\hline $14 i$ & & 4.25 \\
\hline $14 j$ & & 2.52 \\
\hline $14 k$ & & 3.02 \\
\hline 141 & & 5.50 \\
\hline
\end{tabular}


Table 1. Cont.

Compounds

Assays were performed in replicate $(n \geq 3)$, the SD values are $<20 \%$ of the mean.

\subsection{Antiproliferative Activity}

According to the above-described enzyme inhibitory assay results, five of the most potent compounds ( $\mathrm{IC}_{50} \leq 0.50 \mathrm{nM}$ Vs. $12.36 \mathrm{nM}$ of the control drug SAHA) including four alkoxy-substituted derivatives (13a-d) and one benzyloxy-substituted analogue (14m) were further evaluated for their cellular level activities. The in vitro antiproliferative activities of these selected compounds against four human tumor cell lines MDA-MB-231, MCF-7, H157 and A549 were then tested using the SRB assay, and SAHA (1) was also used as the reference compound (Table 2). It was indicated that MDA-MB-231 cells were more sensitive to the tested compounds compared with other cancer cell lines. Notably, both $13 \mathbf{a}\left(\mathrm{IC}_{50}=0.73 \mu \mathrm{M}\right)$ and $13 \mathrm{c}\left(\mathrm{IC}_{50}=0.36 \mu \mathrm{M}\right)$ exhibited obviously better inhibitory activities than SAHA against all cell lines except A549, being 2 3-fold more potent than SAHA.

Table 2. $\mathrm{IC}_{50}$ values $(\mu \mathrm{M})$ of representative compounds against four cancer cell lines.

\begin{tabular}{ccccc}
\hline Compounds & MDA-MB-231 & H157 & A549 & MCF-7 \\
\hline $\mathbf{1 3 a}$ & $0.73 \pm 0.23$ & $1.04 \pm 0.08$ & $5.62 \pm 1.21$ & $2.91 \pm 0.43$ \\
$\mathbf{1 3 b}$ & $1.97 \pm 0.56$ & $1.20 \pm 0.17$ & $4.09 \pm 1.54$ & $2.93 \pm 0.49$ \\
$\mathbf{1 3 c}$ & $0.36 \pm 0.08$ & $0.59 \pm 0.03$ & $2.79 \pm 0.87$ & $1.84 \pm 0.17$ \\
$\mathbf{1 3 d}$ & $1.70 \pm 0.39$ & $2.36 \pm 0.50$ & $4.11 \pm 0.65$ & $5.23 \pm 1.63$ \\
$\mathbf{1 4 m}$ & $1.95 \pm 0.29$ & $4.81 \pm 0.8$ & $7.58 \pm 2.05$ & $6.05 \pm 1.33$ \\
$\mathbf{1}$ & $1.33 \pm 0.61$ & $1.66 \pm 0.14$ & $5.34 \pm 1.09$ & $4.15 \pm 0.74$ \\
\hline
\end{tabular}

Assays were performed in replicate $(n \geq 3)$, the SD values are $<20 \%$ of the mean.

To assess whether the chosen compounds (13a-d) show selectivity between non-cancer cells and cancer cells, the following experiments were performed. Two normal cell lines were selected: human lung epithelial cells (Beas-2B) and human liver epithelial cells (L-02). As shown in Table 3, the results indicated that these compounds displayed no obvious cytotoxicity against the two human normal cells. Particularly, compound 13c behaved even better than SAHA. 
Table 3. Antiproliferative activities $\left(\mathrm{IC}_{50}\right.$ in $\left.\mu \mathrm{M}\right)$ of representative compounds against normal cells.

\begin{tabular}{ccc}
\hline Compounds & Beas-2B & L-02 \\
\hline $\mathbf{1 3 a}$ & $>50$ & $>50$ \\
$\mathbf{1 3 b}$ & $>50$ & $>20$ \\
$\mathbf{1 3 c}$ & $>100$ & $>100$ \\
$\mathbf{1 3 d}$ & $>20$ & $>20$ \\
$\mathbf{1}$ & $>50$ & $>50$
\end{tabular}

Assays were performed in replicate $(n \geq 3)$, the SD values are $<20 \%$ of the mean.

\subsection{Colony Formation Assay}

As all the tested compounds exhibited the best inhibitory activity against MDA-MB-231 cells, our subsequent work then focused on this tumor cell line. The antiproliferative activities of the two best compounds 13a and 13c were further verified by cell cloning experiment and SAHA (1) was used as the positive control. As depicted in Figure 3, when the concentrations of tested compounds were 0.25 $\mu \mathrm{M}$, the effect was almost as good as that of the control drug at $0.5 \mu \mathrm{M}$. Both compounds resulted in a significant inhibition of the colony formation more potently than SAHA, and 13c was especially active. The results suggested that compounds 13a and 13c could at least partly inhibit the growth and development of MDA-MB-231 cells.
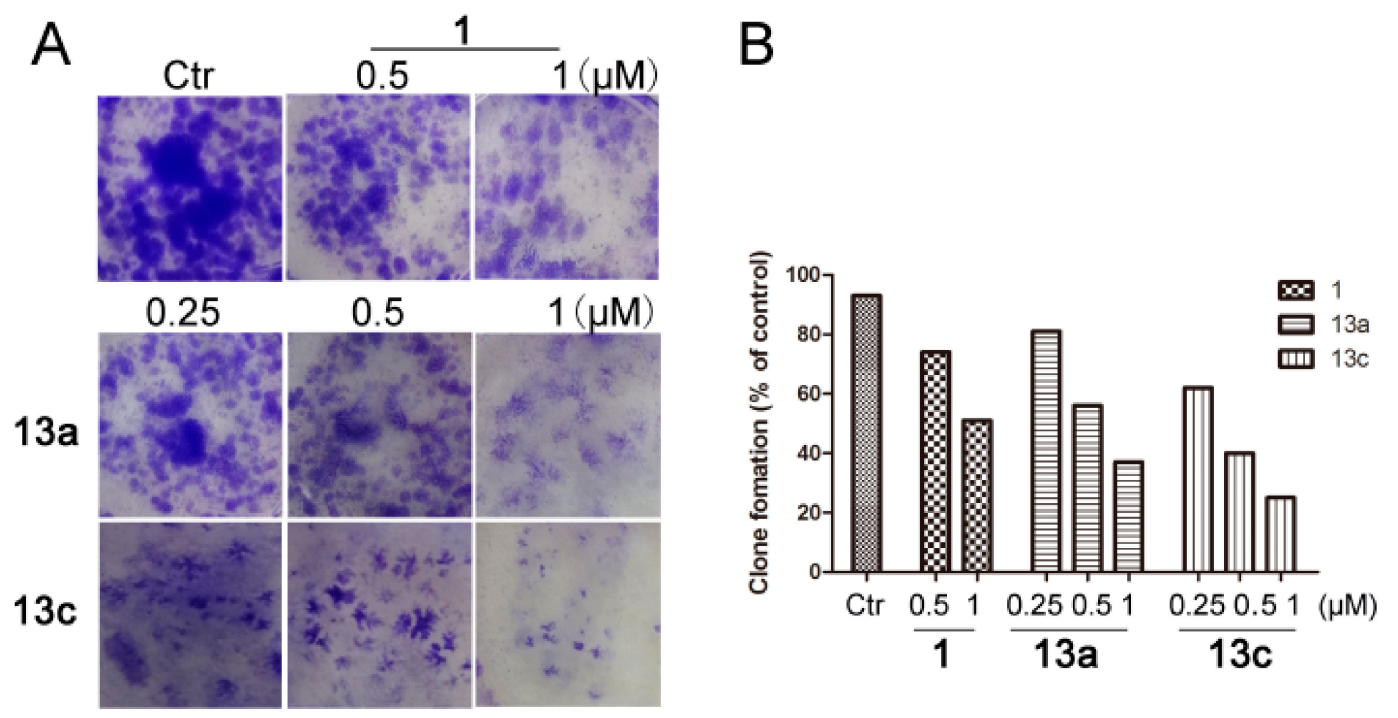

Figure 3. Compounds 13a and 13c inhibited the colony formation of MDA-MB-231 cells. (A) Compounds inhibited the colony formation of MDA-MB-231 cells. After treatment with different concentrations of 13a, 13c and SAHA in six-well plates for seven days, cells were fixed with methanol and stained with $1 \%$ crystal violet and the number of cell clones was counted. (B) Quantitative analysis.

\subsection{Western Blot Analysis}

Based on the aforementioned results, western blot analysis was further performed by immunoblotting assay ( $\beta$-actin as the negative control). MDA-MB-231 cells were incubated with the vehicle alone, SAHA $(5 \mu \mathrm{M}), 13 \mathrm{a}$ and $13 \mathbf{c}(1,2$ and $5 \mu \mathrm{M})$ for $48 \mathrm{~h}$, respectively. As shown in Figure 4, compounds 13a and 13c increased the acetylation levels of histone $\mathrm{H} 3$ and $\mathrm{H} 4$ in a clearly dose-dependent manner. Moreover, the results showed that the levels of acetyl-histone $\mathrm{H} 3$ and H4 in 13a and 13c treated groups were much higher than those in the control group, which was well consistent with their HDAC1 inhibitory activities. 
A

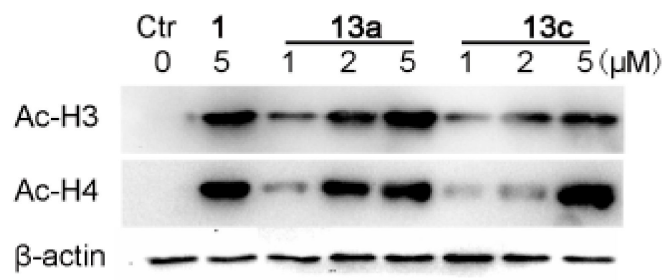

B

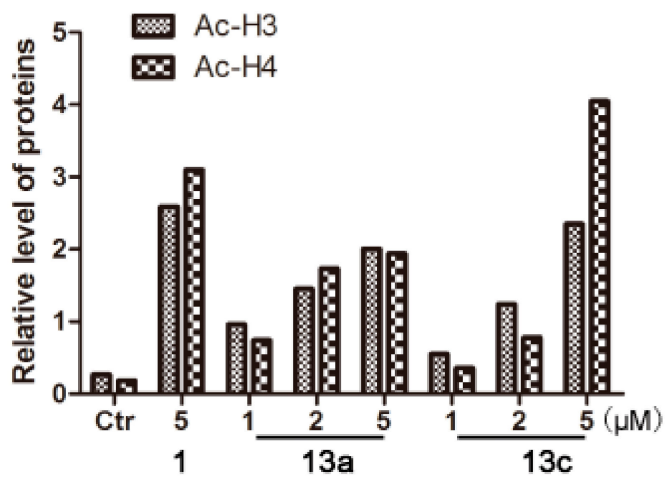

Figure 4. Western blot analysis of the effects of compounds 13a and 13c on acetylated histone levels in MDA-MB-231 cells. (A) MDA-MB-231 cells were treated with 13a, 13c and SAHA for $48 \mathrm{~h}$ at the indicated concentrations, and the levels of protein expression were detected using anti-acetyl-histone $\mathrm{H} 3, \mathrm{H} 4$ and anti- $\beta$-actin antibodies, respectively. $\beta$-Actin was used as the loading control. (B) Quantitative analysis. The relative levels of Ac- $\mathrm{H} 3$ and Ac- $\mathrm{H} 4$ used to control $\beta$-actin were determined by densimetric scanning.

\subsection{Anti-Migration Assay}

HDACis have been reported to suppress the migration of cancer cells [34]. We then evaluated the anti-metastatic activities of compounds 13a and 13c on MDA-MB-231 cells, and SAHA (1) was used as the positive control, as shown in Figure 5. In wound-healing assay, 13a and 13c could obviously inhibit the migration of MDA-MB-231 cells in a dose-dependent and time-dependent manner, both being more potent than SAHA. Even at $48 \mathrm{~h}, \mathbf{1 3} \mathbf{a}$ and $13 \mathrm{c}$ still showed statistically significant anti-metastatic activity at the lowest testing concentration of $0.25 \mu \mathrm{M}$, compared with the SAHA-treated group at $1.0 \mu \mathrm{M}$ (Figure 5B).
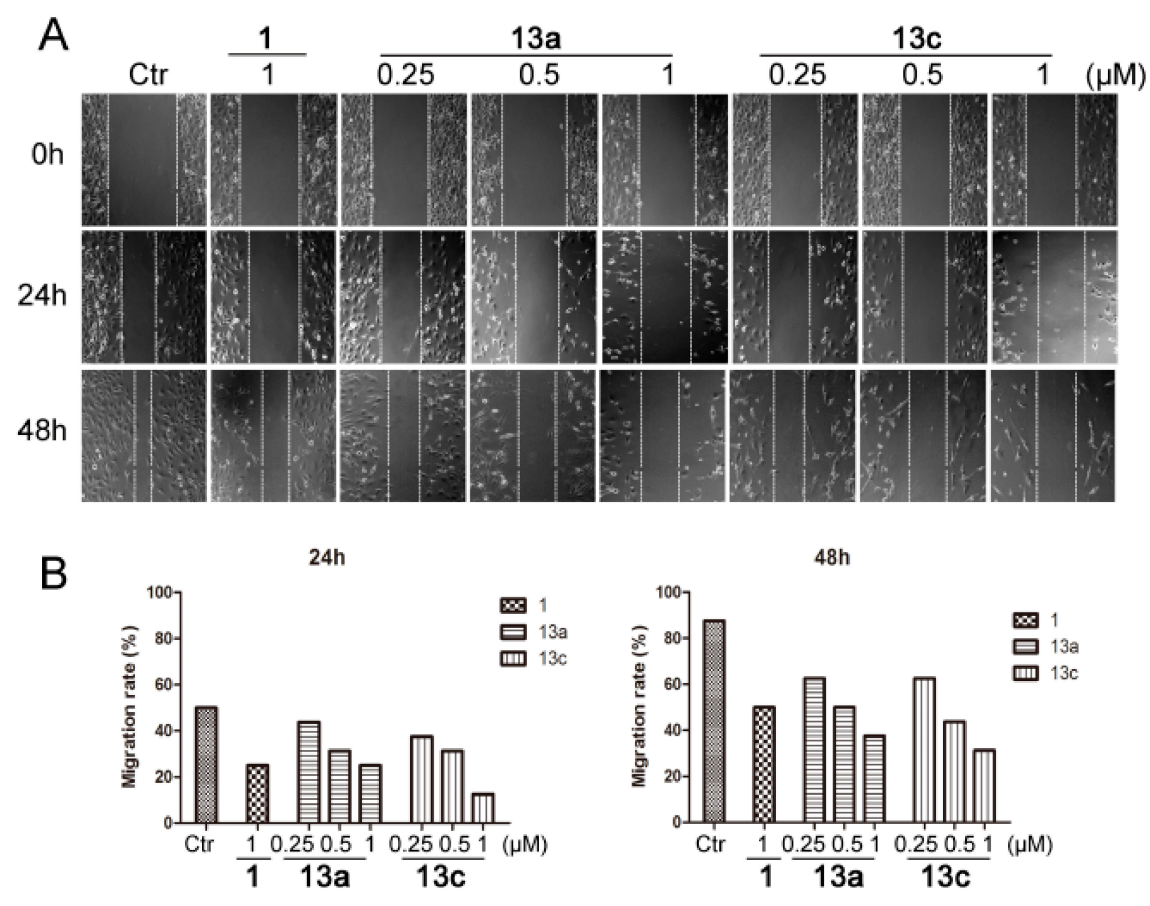

Figure 5. Compounds 13a and 13c inhibited the wound healing of MDA-MB-231 cells. (A) After a wound was made by a pipette tip (in six-well plates), cells were treated with different concentrations of 13a, 13c and SAHA, respectively, and were then photographed at 24 and $48 \mathrm{~h}$. (B) Quantitative analysis. 


\subsection{Cell Cycle Arrest Analysis}

Next, we investigated whether the anti-proliferative activities of 13a and 13c resulted from the induction of cell cycle arrest. As shown in Figure 6, 13a and 13c arrested MDA-MB-231 cells in a dose-dependent manner. In comparison to the control group, compound 13c arrested MDA-MB-231 cells mainly in $\mathrm{G} 2 / \mathrm{M}$ phase $(22.16 \%$ at $1 \mu \mathrm{M})$, which was obviously more potent than SAHA $(11.02 \%$ at $1 \mu \mathrm{M})$.

A
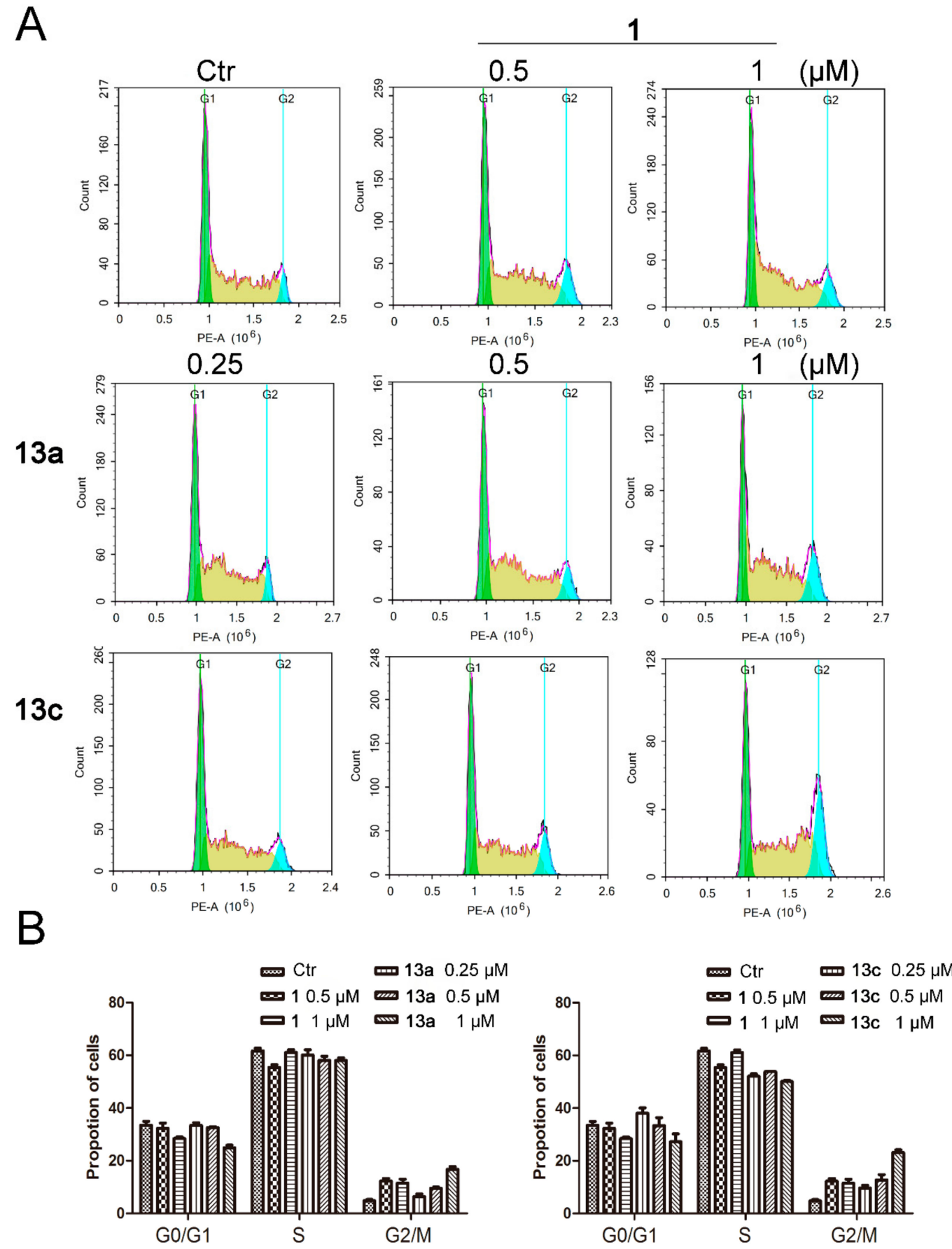

Figure 6. The effects of compounds 13a and 13c on cell cycle progression in MDA-MB-231 cells. (A) MDA-MB-231 cells were treated with SAHA or different doses of 13a and 13c and stained with propidium iodide (PI), followed by flow cytometry analysis. (B) Quantitative analysis. 


\subsection{Apoptosis Analysis}

Finally, we determined whether the anti-proliferative effect of compounds 13a and 13c was related to the induction of cell apoptosis by flow cytometric analysis. As shown in Figure 7, MDA-MB-231 cells arrested were mainly in the early stage of apoptosis. 13a and $\mathbf{1 3} \mathbf{c}$ induced $13.24 \%$ and $19.26 \%$ cell apoptosis at $1 \mu \mathrm{M}$ and induced $18.01 \%$ and $25.14 \%$ cell apoptosis at $2 \mu \mathrm{M}$, respectively. Meanwhile, SAHA (1) only induced $7.3 \%$ and $12.6 \%$ apoptotic cells at 1 and $2 \mu \mathrm{M}$, respectively. The quantitative analysis results clearly indicated that $\mathbf{1 3 a}$ and $\mathbf{1 3} \mathbf{c}$ were able to induce more apoptosis in MDA-MB-231 cells than the references compound $\mathbf{1}$.

A
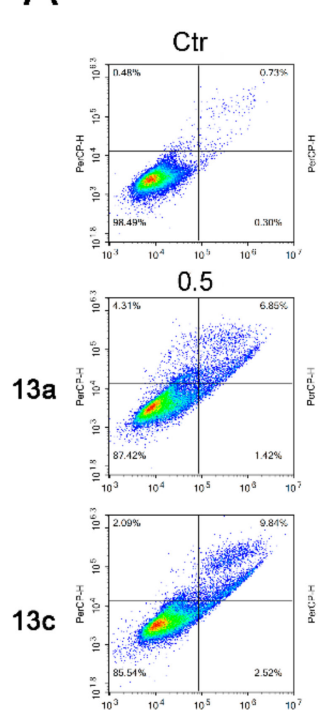
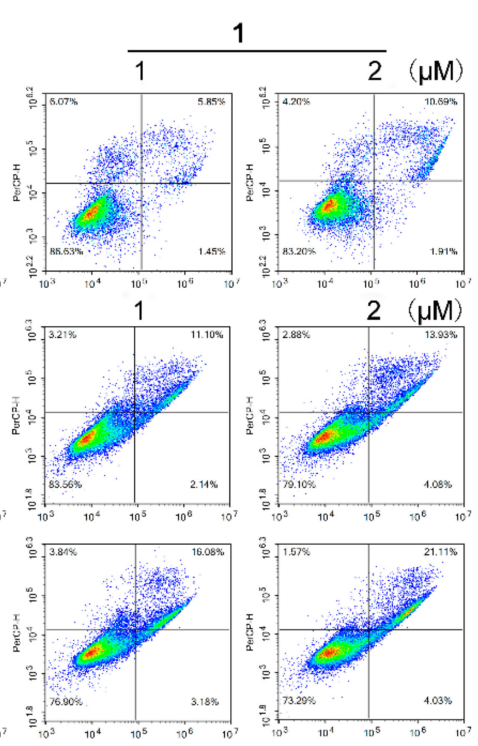

B

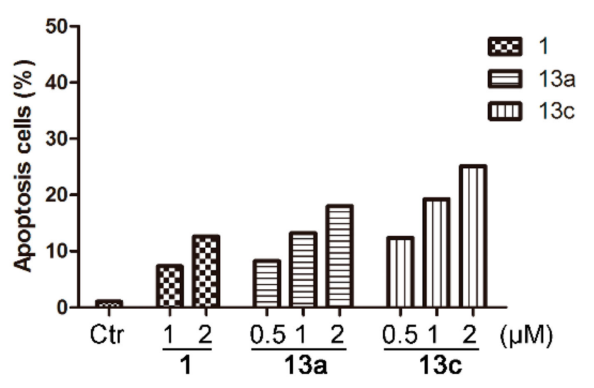

Figure 7. The effects of compounds 13a and 13c on cell apoptotic progression in MDA-MB-231 cells. (A) MDA-MB-231 cells were treated with SAHA or different doses of 13a and 13c and stained with AAD, followed by flow cytometry analysis. (B) Quantitative analysis.

\subsection{Molecular Docking Studies}

Docking simulation was performed for the selected compound $13 \mathrm{c}$ which was docked into HDAC1. Besides chelating with $\mathrm{Zn}^{2+}$, the hydroxamic acid group of $\mathbf{1 3} \mathrm{c}$ formed one and two hydrogen bonds with His140 and His178, respectively (Figure 8 ). Moreover, $\pi-\pi$ interaction was also observed between the phenyl of 13c and Tyr204. 

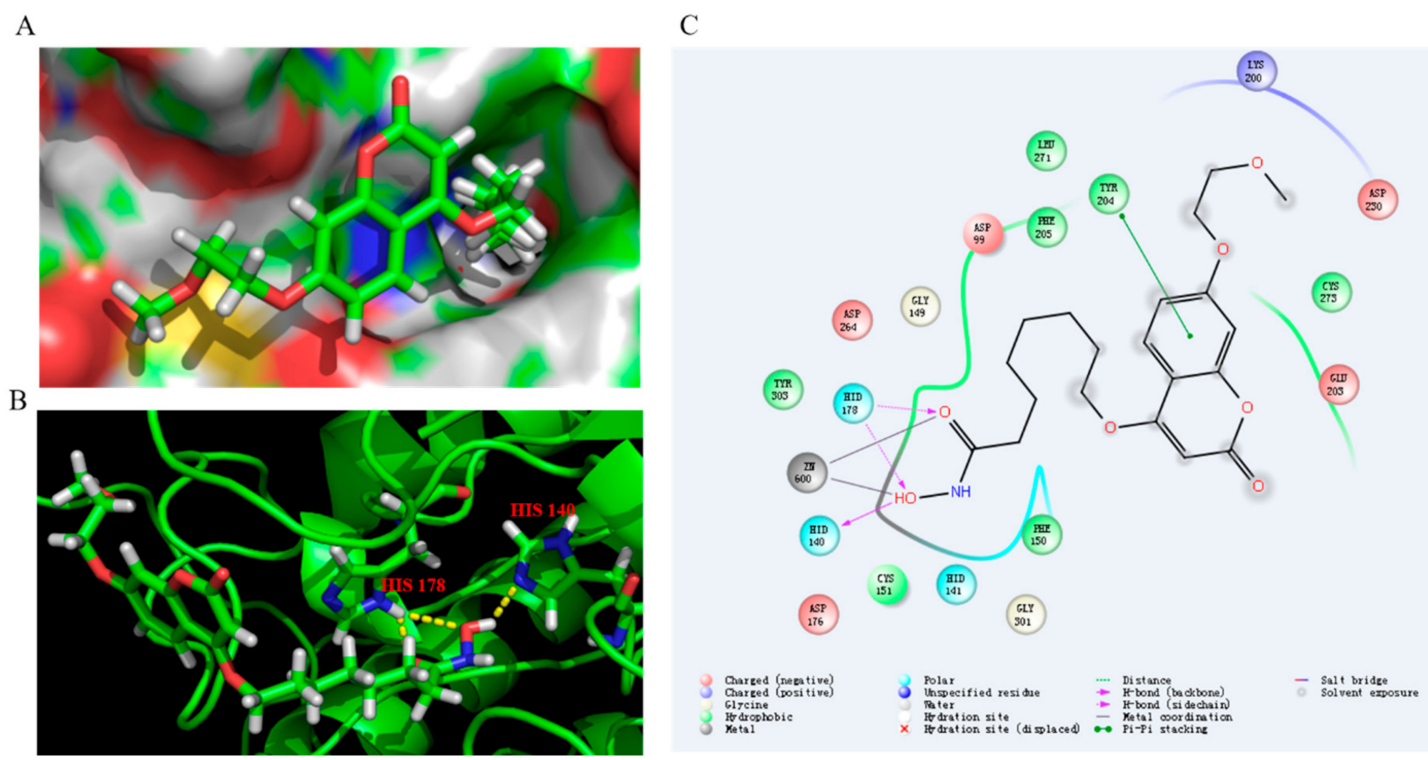

Figure 8. Proposed binding mode of compound 13c with HDAC1 (PDB 4BKX). (A) Molecular surface of the HDAC1 binding pocket with 13c. (B) 13c interacted with the active site of HDAC1. (C) The 2D interaction diagrams of compound 13c with HDAC1.

\section{Experimental Section}

\subsection{Materials and Methods}

Reagents were purchased from Energy Chemical Inc. (Shanghai, China) and Aladdin-reagents Inc. (Shanghai, China), and were used without further purification unless otherwise specified. All reactions were carried out with the use of standard techniques under an inert atmosphere. All target compounds were identified by ${ }^{1} \mathrm{H}$ and ${ }^{13} \mathrm{C}-\mathrm{NMR}$ on a Bruker $600 \mathrm{MHz}$ instrument (Bruker BioSpin AG, Fällanden, Switzerland), as well as HR-ESIMS data. High resolution mass spectra were gathered on an Agilent 6545 Q-TOF mass spectrometer (Agilent Technologies Inc., Waldbronn, Germany) operating in electrospray ionization (ESI) mode. Purity determination was conducted on an Agilent 1260 Series instrument (Agilent Technologies Inc., Waldbronn, Germany) using the following method: Eclipse XDB C18 column, $5 \mu \mathrm{m}, 4.6 \times 150 \mathrm{~mm}$, column temperature $37^{\circ} \mathrm{C}, 1.0 \mathrm{~mL} / \mathrm{min} \mathrm{MeOH}-\mathrm{H}_{2} \mathrm{O}$ system, $60 \%-90 \%$ in $5 \mathrm{~min}$, hold on $5 \mathrm{~min}$, and then back to $60 \%$ in $5 \mathrm{~min}$.

\subsection{General Procedures for Synthesis of $\mathbf{1 3 a}-\mathbf{g}$ and $\mathbf{1 4 a}-\mathbf{s}$}

Compound $8(1.66 \mathrm{~g}, 10 \mathrm{mmol})$ was first subjected to a ring-closing reaction with diethyl carbonate $(1.8 \mathrm{~mL}, 15 \mathrm{mmol})$ and sodium hydride $(2.0 \mathrm{~g}, 50 \mathrm{mmol})$ in toluene $(30 \mathrm{~mL})$ at $115^{\circ} \mathrm{C}$ to give product 9 (1.85 g, 60\% yield), which was subsequently reacted with methyl 8-bromooctanoate (2.52 $\mathrm{g}, 10.59$ $\mathrm{mmol})$ in DMF. The compound 10 (2.31 g, 69\% yield) was demethylated with $\mathrm{BBr}_{3}(1 \mathrm{M}$ in DCM) to afford intermediate $\mathbf{1 1}(1.99 \mathrm{~g}, 90 \%$ yield $)$. Compound $\mathbf{1 1}(200 \mathrm{mg}, 0.59 \mathrm{mmol})$ was further reacted with bromopropane $(94.7 \mathrm{mg}, 0.77 \mathrm{mmol})$.

To a solution of $\mathrm{NH}_{2} \mathrm{OH} \cdot \mathrm{HCl}(875 \mathrm{mg}, 12.6 \mathrm{mmol})$ in $8 \mathrm{~mL} \mathrm{MeOH}, \mathrm{KOH}(706 \mathrm{mg}, 12.6 \mathrm{mmol})$ was added. Then the reaction mixture was stirred at $40{ }^{\circ} \mathrm{C}$ for $10 \mathrm{~min}$ and cooled to $0{ }^{\circ} \mathrm{C}$ and filtered. Methyl-8-((2-oxo-7-propoxy-2H-chromen-4-yl)oxy) octanoate (137 mg, 63\% yield) was added to the filtrate followed by $\mathrm{KOH}(76.3 \mathrm{mg}, 1.36 \mathrm{mmol})$, after which the reaction was stirred at room temperature for $30 \mathrm{~min}$. The solvent was removed and extracted with EtOAc. The obtained residue was finally purified by column chromatography $\left[\mathrm{CH}_{2} \mathrm{Cl}_{2}: \mathrm{MeOH}=10: 1\right]$ to give compound 13a. Compounds $\mathbf{1 3} \mathbf{b}-\mathbf{g}$ and 14a-s were synthesized according to the procedure described for the preparation of 13a. 
N-Hydroxy-8-((2-oxo-7-propoxy-2H-benzopyran-4-yl)oxy)octanoic acid (13a). Yield: 33\%. ${ }^{1} \mathrm{H}-\mathrm{NMR}(600$ $\left.\mathrm{MHz}, \mathrm{CD}_{3} \mathrm{OD}\right) \delta 7.74(\mathrm{~d}, J=8.4 \mathrm{~Hz}, 1 \mathrm{H}), 6.94-6.86(\mathrm{~m}, 2 \mathrm{H}), 5.64(\mathrm{~s}, 1 \mathrm{H}), 5.49(\mathrm{~s}, 2 \mathrm{H}), 4.20(\mathrm{t}, J=6.6 \mathrm{~Hz}$, $2 \mathrm{H}), 4.03(\mathrm{t}, J=6.6 \mathrm{~Hz}, 2 \mathrm{H}), 2.10(\mathrm{t}, J=7.2 \mathrm{~Hz}, 2 \mathrm{H}), 1.93-1.88(\mathrm{~m}, 2 \mathrm{H}), 1.67-1.52(\mathrm{~m}, 4 \mathrm{H}), 1.47-1.36(\mathrm{~m}$, $4 \mathrm{H}), 1.06(\mathrm{t}, J=7.2 \mathrm{~Hz}, 3 \mathrm{H}) .{ }^{13} \mathrm{C}-\mathrm{NMR}\left(150 \mathrm{MHz}, \mathrm{CD}_{3} \mathrm{OD}\right) \delta 172.98,168.36,166.09,164.61,156.40,125.24$, $113.96,109.97,101.91,88.23,71.29,70.82,33.72,30.00,29.97,29.54,26.89,26.65,23.45,10.75$. HRMS (ESI) calcd for $\mathrm{C}_{20} \mathrm{H}_{27} \mathrm{NO}_{6}[\mathrm{M}+\mathrm{H}]^{+}$, 378.1911; found 378.1909. HPLC purity: $98.55 \%$, $\mathrm{t}_{\mathrm{R}}=6.633 \mathrm{~min}$.

N-Hydroxy-8-((7-butoxy-2-oxo-2H-benzopyran-4-yl)oxy)octanoic acid (13b). Yield: 26\%. ${ }^{1} \mathrm{H}-\mathrm{NMR}(600$ MHz, DMSO- $\left.d_{6}\right) \delta 10.34$ (brs, $\left.1 \mathrm{H}\right), 8.67(\mathrm{brs}, 1 \mathrm{H}), 7.67(\mathrm{~d}, J=7.8 \mathrm{~Hz}, 1 \mathrm{H}), 6.95-6.93(\mathrm{~m}, 2 \mathrm{H}), 5.71(\mathrm{~s}, 1 \mathrm{H})$, $4.17(\mathrm{t}, J=6.6 \mathrm{~Hz}, 2 \mathrm{H}), 4.06(\mathrm{t}, J=6.6 \mathrm{~Hz}, 2 \mathrm{H}), 1.95(\mathrm{t}, J=7.2 \mathrm{~Hz}, 2 \mathrm{H}), 1.81-1.69(\mathrm{~m}, 4 \mathrm{H}), 1.52-1.42(\mathrm{~m}$, $6 \mathrm{H}), 1.36-1.24(\mathrm{~m}, 4 \mathrm{H}), 0.94(\mathrm{t}, J=7.2 \mathrm{~Hz}, 3 \mathrm{H}) .{ }^{13} \mathrm{C}-\mathrm{NMR}\left(150 \mathrm{MHz}, \mathrm{DMSO}-d_{6}\right) \delta 169.10,165.45,162.33$, 162.15, 154.64, 123.89, 112.54, 108.26, 100.94, 87.79, 69.27, 67.99, 32.24, 30.49, 28.48, 28.36, 27.94, 25.31, 25.06, 18.68, 13.67. HRMS (ESI) calcd for $\mathrm{C}_{21} \mathrm{H}_{29} \mathrm{NO}_{6}[\mathrm{M}+\mathrm{H}]^{+}$392.2068; found 392.2067. HPLC purity: $98.70 \%, \mathrm{t}_{\mathrm{R}}=7.665 \mathrm{~min}$.

N-Hydroxy-8-((7-(2-methoxyethoxy)-2-oxo-2H-chromen-4-yl)oxy)octanoic acid (13c). Yield: $27 \% .{ }^{1} \mathrm{H}-\mathrm{NMR}$ $\left(600 \mathrm{MHz}, \mathrm{CD}_{3} \mathrm{OD}\right) \delta 7.76(\mathrm{~d}, J=7.8 \mathrm{~Hz}, 1 \mathrm{H}), 6.97-6.91(\mathrm{~m}, 2 \mathrm{H}), 5.66(\mathrm{~s}, 1 \mathrm{H}), 4.22-4.19(\mathrm{~m}, 4 \mathrm{H}), 3.78-3.77$ $(\mathrm{m}, 2 \mathrm{H}), 3.43(\mathrm{~s}, 3 \mathrm{H}), 2.10(\mathrm{t}, J=7.2 \mathrm{~Hz}, 2 \mathrm{H}), 1.93-1.89(\mathrm{~m}, 2 \mathrm{H}), 1.67-1.53(\mathrm{~m}, 4 \mathrm{H}), 1.47-1.37(\mathrm{~m}, 4 \mathrm{H})$. ${ }^{13} \mathrm{C}-\mathrm{NMR}\left(150 \mathrm{MHz}, \mathrm{CD}_{3} \mathrm{OD}\right) \delta 168.29,166.00,164.25,156.35,125.32,113.97,110.29,102.13,88.41,71.90$, $70.85,69.12,59.27,33.71,30.00,29.97,29.54,26.89,26.65$. HRMS (ESI) calcd for $\mathrm{C}_{20} \mathrm{H}_{27} \mathrm{NO}_{7}[\mathrm{M}+\mathrm{H}]^{+}$ 394.1860; found 394.1863. HPLC purity: $95.43 \%, \mathrm{t}_{\mathrm{R}}=8.571 \mathrm{~min}$.

N-Hydroxy-8-((7-(3-methoxypropoxy)-2-oxo-2H-chromen-4-yl)oxy)octanoic acid (13d). Yield: $23 \% .{ }^{1} \mathrm{H}-\mathrm{NMR}$ $\left(600 \mathrm{MHz}, \mathrm{DMSO}-d_{6}\right) \delta 10.32$ (brs, $\left.1 \mathrm{H}\right), 8.65(\mathrm{brs}, 1 \mathrm{H}), 7.68(\mathrm{~d}, J=7.8 \mathrm{~Hz}, 1 \mathrm{H}), 6.95-6.94(\mathrm{~m}, 2 \mathrm{H}), 5.75(\mathrm{~s}$, $1 \mathrm{H}), 4.17(\mathrm{t}, J=6.6 \mathrm{~Hz}, 2 \mathrm{H}), 4.11(\mathrm{t}, J=6.6 \mathrm{~Hz}, 2 \mathrm{H}), 3.47(\mathrm{t}, J=6.6 \mathrm{~Hz}, 2 \mathrm{H}), 3.25(\mathrm{~s}, 3 \mathrm{H}), 1.99-1.93(\mathrm{~m}$, $4 \mathrm{H}), 1.82-1.79(\mathrm{~m}, 2 \mathrm{H}), 1.52-1.41(\mathrm{~m}, 4 \mathrm{H}), 1.36-1.24(\mathrm{~m}, 4 \mathrm{H}) .{ }^{13} \mathrm{C}-\mathrm{NMR}\left(150 \mathrm{MHz}, \mathrm{DMSO}-d_{6}\right) \delta 169.11$, $165.42,162.18,162.13,154.61,123.94,112.47,108.36,101.02,87.86,69.28,68.30,65.42,57.98,32.24,28.72$, 28.47, 28.35, 27.93, 25.30, 25.05. HRMS (ESI) calcd for $\mathrm{C}_{21} \mathrm{H}_{29} \mathrm{NO}_{7}[\mathrm{M}+\mathrm{H}]^{+}$408.2017; found 408.2015. HPLC purity: $98.36 \%, \mathrm{t}_{\mathrm{R}}=5.657 \mathrm{~min}$.

N-Hydroxy-8-((7-(2-(benzyloxy)ethoxy)-2-oxo-2H-chromen-4-yl)oxy)octanamide (13e). Yield: 29\%. ${ }^{1} \mathrm{H}-\mathrm{NMR}$ $\left(600 \mathrm{MHz}, \mathrm{DMSO}-d_{6}\right) \delta 10.33$ (brs, $\left.1 \mathrm{H}\right), 8.65$ (brs, $\left.1 \mathrm{H}\right), 7.67(\mathrm{~d}, J=8.4 \mathrm{~Hz}, 1 \mathrm{H}), 7.35-7.27(\mathrm{~m}, 5 \mathrm{H})$, $7.00-6.96(\mathrm{~m}, 2 \mathrm{H}), 5.72(\mathrm{~s}, 1 \mathrm{H}), 4.56(\mathrm{~s}, 2 \mathrm{H}), 4.26-4.24(\mathrm{~m}, 2 \mathrm{H}), 4.18(\mathrm{t}, J=6.0 \mathrm{~Hz}, 2 \mathrm{H}), 3.80-3.78(\mathrm{~m}, 2 \mathrm{H})$, $1.94(\mathrm{t}, J=7.2 \mathrm{~Hz}, 2 \mathrm{H}), 1.82-1.77(\mathrm{~m}, 2 \mathrm{H}), 1.52-1.41(\mathrm{~m}, 4 \mathrm{H}), 1.36-1.24(\mathrm{~m}, 4 \mathrm{H}) .{ }^{13} \mathrm{C}-\mathrm{NMR}(150 \mathrm{MHz}$, DMSO- $\left.d_{6}\right) \delta 169.09,165.40,162.10,154.57,138.22,128.26,127.56,127.48,123.92,112.61,108.42,101.08$, 87.89, 72.07, 69.27, 67.94, 67.87, 32.23, 28.46, 28.34, 27.92, 25.29, 25.04. HRMS (ESI) calcd for $\mathrm{C}_{26} \mathrm{H}_{31} \mathrm{NO}_{7}$ $[\mathrm{M}+\mathrm{H}]^{+}$470.2173; found 470.2170. HPLC purity: $97.06 \%, \mathrm{t}_{\mathrm{R}}=8.193 \mathrm{~min}$.

N-Hydroxy-8-((7-isobutoxy-2-oxo-2H-chromen-4-yl)oxy)octanoic acid (13f). Yield: 27\%. ${ }^{1} \mathrm{H}-\mathrm{NMR}(600$ $\left.\mathrm{MHz}, \mathrm{CD}_{3} \mathrm{OD}\right) \delta 7.74(\mathrm{~d}, J=8.4 \mathrm{~Hz}, 1 \mathrm{H}), 6.94-6.85(\mathrm{~m}, 2 \mathrm{H}), 5.64(\mathrm{~s}, 1 \mathrm{H}), 4.19(\mathrm{t}, J=6.6 \mathrm{~Hz}, 2 \mathrm{H}), 3.84(\mathrm{~d}$, $J=6.6 \mathrm{~Hz}, 2 \mathrm{H}), 2.11-2.09(\mathrm{~m}, 3 \mathrm{H}), 1.92-1.88(\mathrm{~m}, 2 \mathrm{H}), 1.67-1.52(\mathrm{~m}, 4 \mathrm{H}), 1.47-1.39(\mathrm{~m}, 4 \mathrm{H}), 1.05(\mathrm{~d}, J=$ $6.6 \mathrm{~Hz}, 6 \mathrm{H}) .{ }^{13} \mathrm{C}-\mathrm{NMR}\left(150 \mathrm{MHz}, \mathrm{CD}_{3} \mathrm{OD}\right) \delta 172.96,168.35,166.08,164.66,156.39,125.24,113.95,109.98$, $101.92,88.24,76.04,70.82,33.72,30.00,29.98,29.54,29.42,26.89,26.65,19.42$. HRMS (ESI) calcd for $\mathrm{C}_{21} \mathrm{H}_{29} \mathrm{NO}_{6}[\mathrm{M}+\mathrm{H}]^{+}$392.2068; found 392.2071. HPLC purity: $98.45 \%, \mathrm{t}_{\mathrm{R}}=7.239 \mathrm{~min}$.

N-Hydroxy-8-((7-(cyclohexyl)-2-oxo-2H-benzopyran-4-yl)oxy)octanoic acid (13g). Yield: 30\%. ${ }^{1} \mathrm{H}-\mathrm{NMR}(600$ MHz, DMSO- $\left.d_{6}\right) \delta 10.33(\mathrm{brs}, 1 \mathrm{H}), 8.65(\mathrm{brs}, 1 \mathrm{H}), 7.67(\mathrm{~d}, J=7.8 \mathrm{~Hz}, 1 \mathrm{H}), 6.95-6.93(\mathrm{~m}, 2 \mathrm{H}), 5.71(\mathrm{~s}, 1 \mathrm{H})$, $4.17(\mathrm{t}, J=6.0 \mathrm{~Hz}, 2 \mathrm{H}), 3.88(\mathrm{~d}, J=5.4 \mathrm{~Hz}, 2 \mathrm{H}), 1.94(\mathrm{t}, J=7.2 \mathrm{~Hz}, 2 \mathrm{H}), 1.81-1.64(\mathrm{~m}, 8 \mathrm{H}), 1.52-1.43$ $(\mathrm{m}, 4 \mathrm{H}), 1.36-1.23(\mathrm{~m}, 7 \mathrm{H}), 1.38-1.02(\mathrm{~m}, 2 \mathrm{H}) .{ }^{13} \mathrm{C}-\mathrm{NMR}\left(150 \mathrm{MHz}, \mathrm{DMSO}-d_{6}\right) \delta 169.10,165.44,162.43$, $162.14,154.62,123.89,112.53,108.23,100.98,87.79,73.34,69.26,36.90,32.23,29.12,28.46,28.34,27.93$, 25.99, 25.29, 25.21, 25.04. HRMS (ESI) calcd for $\mathrm{C}_{24} \mathrm{H}_{33} \mathrm{NO}_{6}[\mathrm{M}+\mathrm{H}]^{+} 432.2381$; found 432.2383. HPLC purity: $97.11 \%, \mathrm{t}_{\mathrm{R}}=8.778 \mathrm{~min}$. 
N-Hydroxy-8-((7-(oxy)-2-oxo-2H-benzopyran-4-yl)oxy)octanoic acid (14a). Yield: 31\%. ${ }^{1} \mathrm{H}-\mathrm{NMR}(600 \mathrm{MHz}$, DMSO- $d_{6}$ ) $\delta 10.33$ (brs, $\left.1 \mathrm{H}\right), 8.65$ (brs, $\left.1 \mathrm{H}\right), 7.70(\mathrm{~d}, J=7.8 \mathrm{~Hz}, 1 \mathrm{H}), 7.47(\mathrm{~d}, J=7.8 \mathrm{~Hz}, 2 \mathrm{H}), 7.41$ (dd, $J=7.8 \mathrm{~Hz}, 7.8 \mathrm{~Hz}, 2 \mathrm{H}), 7.35(\mathrm{dd}, J=7.8 \mathrm{~Hz}, 7.8 \mathrm{~Hz}, 1 \mathrm{H}), 7.07-7.02(\mathrm{~m}, 2 \mathrm{H}), 5.73(\mathrm{~s}, 1 \mathrm{H}), 5.21(\mathrm{~s}, 2 \mathrm{H})$, $4.18(\mathrm{t}, J=6.6 \mathrm{~Hz}, 2 \mathrm{H}), 1.94(\mathrm{t}, J=7.2 \mathrm{~Hz}, 2 \mathrm{H}), 1.82-1.77(\mathrm{~m}, 2 \mathrm{H}), 1.52-1.41(\mathrm{~m}, 4 \mathrm{H}), 1.36-1.23(\mathrm{~m}, 4 \mathrm{H})$. ${ }^{13} \mathrm{C}-\mathrm{NMR}\left(150 \mathrm{MHz}, \mathrm{DMSO}-d_{6}\right) \delta 169.10,165.38,162.08,161.88,154.54,136.22,128.53,128.13,127.95$, $123.97,112.83,108.57,101.47,87.96,69.90,69.29,32.23,28.47,28.34,27.93,25.29,25.04$. HRMS (ESI) calcd for $\mathrm{C}_{24} \mathrm{H}_{27} \mathrm{NO}_{6}[\mathrm{M}+\mathrm{H}]^{+}$426.1911; found 426.1906. HPLC purity: 96.83\%, $\mathrm{t}_{\mathrm{R}}=8.498 \mathrm{~min}$.

N-Hydroxy-8-((7-((2-nitrobenzyl)oxy)-2-oxo-2H-chromen-4-yl)oxy)octanoic acid (14b). Yield: 23\%. ${ }^{1} \mathrm{H}-\mathrm{NMR}$ $\left(600 \mathrm{MHz}, \mathrm{DMSO}-d_{6}\right) \delta 10.33$ (brs, $\left.1 \mathrm{H}\right), 8.65$ (brs, $\left.1 \mathrm{H}\right), 7.80-7.69(\mathrm{~m}, 2 \mathrm{H}), 7.53-7.35(\mathrm{~m}, 3 \mathrm{H}), 7.09-7.01$ $(\mathrm{m}, 2 \mathrm{H}), 5.75-5.73(\mathrm{~m}, 1 \mathrm{H}), 5.21-5.12(\mathrm{~m}, 2 \mathrm{H}), 4.18(\mathrm{~s}, 2 \mathrm{H}), 1.94(\mathrm{t}, J=7.2 \mathrm{~Hz}, 2 \mathrm{H}), 1.80(\mathrm{~s}, 2 \mathrm{H}), 1.52-1.43$ (m, 4H), 1.35-1.23 (m, 4H). ${ }^{13} \mathrm{C}-\mathrm{NMR}\left(150 \mathrm{MHz}, \mathrm{DMSO}-d_{6}\right) \delta 169.11,165.37,162.09,154.54,130.42$, 130.18, 128.54, 126.81, 125.09, 118.93, 112.61, 108.68, 101.41, 69.31, 65.78, 32.23, 28.46, 28.34, 27.93, 25.29, 25.04. HRMS (ESI) calcd for $\mathrm{C}_{24} \mathrm{H}_{26} \mathrm{~N}_{2} \mathrm{O}_{8}[\mathrm{M}+\mathrm{H}]^{+} 471.1762$; found 471.1761 . HPLC purity: $98.92 \%$, $\mathrm{t}_{\mathrm{R}}$ $=8.400 \mathrm{~min}$.

N-Hydroxy-8-((7-((3-nitrobenzyl)oxy)-2-oxo-2H-chromen-4-yl)oxy)octanoic acid (14c). Yield: $22 \% .{ }^{1} \mathrm{H}-\mathrm{NMR}$ $\left(600 \mathrm{MHz}, \mathrm{CD}_{3} \mathrm{OD}\right) \delta 7.75(\mathrm{~d}, J=8.6 \mathrm{~Hz}, 1 \mathrm{H}), 7.46(\mathrm{~d}, J=7.2 \mathrm{~Hz}, 1 \mathrm{H}), 7.39(\mathrm{dd}, J=7.2 \mathrm{~Hz}, 7.2 \mathrm{~Hz}, \mathrm{H})$, $7.33(\mathrm{dd}, J=7.2 \mathrm{~Hz}, 7.2 \mathrm{~Hz}, 1 \mathrm{H}), 7.16-7.00(\mathrm{~m}, 2 \mathrm{H}), 6.95(\mathrm{~s}, 1 \mathrm{H}), 5.49(\mathrm{~s}, 1 \mathrm{H}), 5.17(\mathrm{~s}, 2 \mathrm{H}), 4.19(\mathrm{t}, J=$ $6.0 \mathrm{~Hz}, 2 \mathrm{H}), 2.10(\mathrm{t}, J=7.2 \mathrm{~Hz}, 2 \mathrm{H}), 1.91-1.89(\mathrm{~m}, 2 \mathrm{H}), 1.67-1.53(\mathrm{~m}, 4 \mathrm{H}), 1.44-1.38(\mathrm{~m}, 4 \mathrm{H}) .{ }^{13} \mathrm{C}-\mathrm{NMR}$ $\left(150 \mathrm{MHz}, \mathrm{CD}_{3} \mathrm{OD}\right) \delta 172.98,168.25,165.98,164.08,156.30,137.71,129.64,129.22,128.75,125.31,119.67$, $119.00,114.25,110.31,102.54,88.42,71.58,70.84,33.72,29.98,29.97,29.53,26.88,26.64$. HRMS (ESI) calcd for $\mathrm{C}_{24} \mathrm{H}_{26} \mathrm{~N}_{2} \mathrm{O}_{8}[\mathrm{M}+\mathrm{H}]^{+}$471.1762; found 471.1761. HPLC purity: $98.94 \%, \mathrm{t}_{\mathrm{R}}=8.391 \mathrm{~min}$.

N-Hydroxy-8-((7-((4-nitrobenzyl)oxy)2-oxo-2H-chromen-4-yl)oxy)octanoic acid (14d). Yield: $23 \% .{ }^{1} \mathrm{H}-\mathrm{NMR}$ $\left(600 \mathrm{MHz}\right.$, DMSO- $\left.d_{6}\right) \delta 10.33$ (brs, $\left.1 \mathrm{H}\right), 8.65$ (brs, $\left.1 \mathrm{H}\right), 8.27(\mathrm{~d}, J=7.8 \mathrm{~Hz}, 1 \mathrm{H}), 7.75-7.68(\mathrm{~m}, 2 \mathrm{H})$, $7.58-7.35(\mathrm{~m}, 2 \mathrm{H}), 7.16-7.06(\mathrm{~m}, 2 \mathrm{H}), 5.73(\mathrm{~d}, J=8.4 \mathrm{~Hz}, 1 \mathrm{H}), 5.40-5.20(\mathrm{~m}, 2 \mathrm{H}), 4.18(\mathrm{t}, J=6.0 \mathrm{~Hz}, 2 \mathrm{H})$, $1.94(\mathrm{t}, J=7.2 \mathrm{~Hz}, 2 \mathrm{H}), 1.81-1.77(\mathrm{~m}, 2 \mathrm{H}), 1.52-1.41(\mathrm{~m}, 4 \mathrm{H}), 1.36-1.24(\mathrm{~m}, 4 \mathrm{H}) .{ }^{13} \mathrm{C}-\mathrm{NMR}(150 \mathrm{MHz}$, DMSO- $d_{6}$ ) $\delta 169.10,165.35,162.06,161.67,154.52,135.29,132.71,129.76,128.54,124.00,112.81,108.68$, $101.51,88.02,69.31,69.01,32.23,28.46,28.34,27.92,25.29,25.04$. HRMS (ESI) calcd for $\mathrm{C}_{24} \mathrm{H}_{26} \mathrm{~N}_{2} \mathrm{O}_{8}$ $[\mathrm{M}+\mathrm{H}]^{+}$471.1758; found 471.1762. HPLC purity: $99.00 \%, \mathrm{t}_{\mathrm{R}}=8.393 \mathrm{~min}$.

N-Hydroxy-8-((7-((2-fluorobenzyl)oxy)-2-oxo-2H-chromen-4-yl)oxy)octanoic acid (14e). Yield: 28\%. ${ }^{1} \mathrm{H}-\mathrm{NMR}$ $\left(600 \mathrm{MHz}\right.$, DMSO- $\left.d_{6}\right) \delta 10.33(\mathrm{brs}, 1 \mathrm{H}), 8.65(\mathrm{brs}, 1 \mathrm{H}), 7.71(\mathrm{~d}, J=8.4 \mathrm{~Hz}, 1 \mathrm{H}), 7.60-7.58(\mathrm{dd}, J=7.8 \mathrm{~Hz}$, $7.8 \mathrm{~Hz}, 1 \mathrm{H}), 7.47-7.44(\mathrm{~m}, 1 \mathrm{H}), 7.29-7.24(\mathrm{~m}, 2 \mathrm{H}), 7.12-7.02(\mathrm{~m}, 2 \mathrm{H}), 5.74(\mathrm{~s}, 1 \mathrm{H}), 5.25(\mathrm{~s}, 2 \mathrm{H}), 4.18(\mathrm{t}, J=$ $6.0 \mathrm{~Hz}, 2 \mathrm{H}), 1.94(\mathrm{t}, J=7.2 \mathrm{~Hz}, 2 \mathrm{H}), 1.82-1.77(\mathrm{~m}, 2 \mathrm{H}), 1.52-1.42(\mathrm{~m}, 4 \mathrm{H}), 1.36-1.23(\mathrm{~m}, 4 \mathrm{H}) .{ }^{13} \mathrm{C}-\mathrm{NMR}$ $\left(150 \mathrm{MHz}, \mathrm{DMSO}-d_{6}\right) \delta 169.13,165.38,162.11,161.71,154.56,131.05,130.86,124.64,124.05,123.08$, $115.59,115.46,112.70,18.76,101.43,88.07,69.33,64.32,32.25,28.48,28.36,27.94,25.31,25.06$. HRMS (ESI) calcd for $\mathrm{C}_{24} \mathrm{H}_{26} \mathrm{FNO}_{6}[\mathrm{M}+\mathrm{H}]^{+}$444.1817; found 444.1815. HPLC purity: $96.93 \%, \mathrm{t}_{\mathrm{R}}=8.151 \mathrm{~min}$.

N-Hydroxy-8-((7-((3-fluorobenzyl)oxy)-2-oxo-2H-chromen-4-yl)oxy)octanoic acid (14f). Yield: 29\%. ${ }^{1} \mathrm{H}-\mathrm{NMR}$ $\left(600 \mathrm{MHz}, \mathrm{DMSO}-d_{6}\right) \delta 10.32$ (brs, $\left.1 \mathrm{H}\right), 8.65$ (brs, $\left.1 \mathrm{H}\right), 7.70(\mathrm{~d}, J=7.8 \mathrm{~Hz}, 1 \mathrm{H}), 7.47-7.44(\mathrm{~m}, 1 \mathrm{H}), 7.32(\mathrm{~d}$, $J=7.2 \mathrm{~Hz}, 2 \mathrm{H}), 7.20-7.17(\mathrm{~m}, 1 \mathrm{H}), 7.07-7.03(\mathrm{~m}, 2 \mathrm{H}), 5.73(\mathrm{~s}, 1 \mathrm{H}), 5.24(\mathrm{~s}, 2 \mathrm{H}), 4.18(\mathrm{t}, J=6.3 \mathrm{~Hz}, 2 \mathrm{H})$, $1.94(\mathrm{t}, J=7.2 \mathrm{~Hz}, 2 \mathrm{H}), 1.82-1.77(\mathrm{~m}, 2 \mathrm{H}), 1.52-1.41(\mathrm{~m}, 4 \mathrm{H}), 1.36-1.24(\mathrm{~m}, 4 \mathrm{H}) .{ }^{13} \mathrm{C}-\mathrm{NMR}(150 \mathrm{MHz}$, DMSO- $\left.d_{6}\right) \delta 169.09,165.34,162.05,161.63,154.51,139.12,130.62,124.01,123.78,123.76,114.94,114.54$, $112.79,108.72,101.52,88.04,69.30,56.02,32.23,30.70,28.46,27.92,25.29,25.04$. HRMS (ESI) calcd for $\mathrm{C}_{24} \mathrm{H}_{26} \mathrm{FNO}_{6}[\mathrm{M}+\mathrm{H}]^{+}$444.1817; found 444.1816. HPLC purity: $97.07 \%, \mathrm{t}_{\mathrm{R}}=8.510 \mathrm{~min}$.

N-Hydroxy-8-((7-((4-fluorobenzyl)oxy)2-oxo-2H-chromen-4yl)oxy)octanoic acid (14g). Yield: 30\%. ${ }^{1} \mathrm{H}-\mathrm{NMR}$ $\left(600 \mathrm{MHz}, \mathrm{DMSO}-d_{6}\right) \delta 10.33$ (brs, $\left.1 \mathrm{H}\right), 8.66(\mathrm{brs}, 1 \mathrm{H}), 7.70(\mathrm{~d}, J=8.8 \mathrm{~Hz}, 1 \mathrm{H}), 7.54-7.52(\mathrm{~m}, 2 \mathrm{H})$, $7.25-7.22(\mathrm{~m}, 2 \mathrm{H}), 7.07-7.01(\mathrm{~m}, 2 \mathrm{H}), 5.73(\mathrm{~s}, 1 \mathrm{H}), 5.19(\mathrm{~s}, 2 \mathrm{H}), 4.18(\mathrm{t}, J=6.3 \mathrm{~Hz}, 2 \mathrm{H}), 1.94(\mathrm{t}, J=7.2 \mathrm{~Hz}$, 2H), $1.83-1.78(\mathrm{~m}, 2 \mathrm{H}), 1.52-1.41(\mathrm{~m}, 4 \mathrm{H}), 1.36-1.24(\mathrm{~m}, 4 \mathrm{H}) .{ }^{13} \mathrm{C}-\mathrm{NMR}\left(150 \mathrm{MHz}, \mathrm{DMSO}-d_{6}\right) \delta 169.13$, $165.39,162.11,161.79,154.55,132.47,130.34,124.00,115.46,115.31,112.84,108.63,101.49,88.00,69.32$, 
69.18, 32.25, 28.48, 28.35, 27.94, 25.30, 25.06. HRMS (ESI) calcd for $\mathrm{C}_{24} \mathrm{H}_{26} \mathrm{FNO}_{6}[\mathrm{M}+\mathrm{H}]^{+}$444.1817; found 444.1819 . HPLC purity: $98.68 \%, \mathrm{t}_{\mathrm{R}}=8.446 \mathrm{~min}$.

N-Hydroxy-8-((7-((2-chlorobenzyl)oxy)-2-oxo-2H-chromen-4-yl)oxy)octanoic acid (14h). Yield: 23\%. ${ }^{1} \mathrm{H}-\mathrm{NMR}\left(600 \mathrm{MHz}\right.$, DMSO- $\left.d_{6}\right) \delta 10.33$ (brs, $\left.1 \mathrm{H}\right), 8.65$ (brs, $\left.1 \mathrm{H}\right), 7.71(\mathrm{~d}, J=8.4 \mathrm{~Hz}, 1 \mathrm{H}), 7.63(\mathrm{~d}$, $J=7.2 \mathrm{~Hz}, 1 \mathrm{H}), 7.54(\mathrm{~d}, J=7.2 \mathrm{~Hz}, 1 \mathrm{H}), 7.44-7.39(\mathrm{~m}, 2 \mathrm{H}), 7.11-7.03(\mathrm{~m}, 2 \mathrm{H}), 5.74(\mathrm{~s}, 1 \mathrm{H}), 5.26(\mathrm{~s}, 2 \mathrm{H})$, $4.18(\mathrm{t}, J=6.0 \mathrm{~Hz}, 2 \mathrm{H}), 1.94(\mathrm{t}, J=7.2 \mathrm{~Hz}, 2 \mathrm{H}), 1.83-1.77(\mathrm{~m}, 2 \mathrm{H}), 1.52-1.42(\mathrm{~m}, 4 \mathrm{H}), 1.36-1.24(\mathrm{~m}, 4 \mathrm{H})$. ${ }^{13} \mathrm{C}-\mathrm{NMR}\left(150 \mathrm{MHz}, \mathrm{DMSO}-d_{6}\right) \delta 169.10,165.34,162.06,161.70,154.53,133.51,132.96,130.61,130.27$, $129.51,127.47,124.06,112.63,108.81,101.48,88.07,69.31,67.61,32.23,28.47,28.34,27.92,25.29,25.04$. HRMS (ESI) calcd for $\mathrm{C}_{24} \mathrm{H}_{26} \mathrm{ClNO}_{6}[\mathrm{M}+\mathrm{H}]^{+} 460.1521$; found 460.1522 . HPLC purity: $98.15 \%$, $\mathrm{t}_{\mathrm{R}}=$ $9.287 \mathrm{~min}$.

N-Hydroxy-8-((7-((3-chlorobenzyl)oxy)-2-oxo-2H-chromen-4-yl)oxy)octanoic acid (14i). Yield: 33\%. ${ }^{1} \mathrm{H}-\mathrm{NMR}$ $\left(600 \mathrm{MHz}, \mathrm{DMSO}-d_{6}\right) \delta 10.33$ (brs, $\left.1 \mathrm{H}\right), 8.65(\mathrm{brs}, 1 \mathrm{H}), 7.70(\mathrm{~d}, J=7.8 \mathrm{~Hz}, 1 \mathrm{H}), 7.55(\mathrm{~s}, 1 \mathrm{H}), 7.45-7.42(\mathrm{~m}$, $3 \mathrm{H}), 7.07-7.03(\mathrm{~m}, 2 \mathrm{H}), 5.73(\mathrm{~s}, 1 \mathrm{H}), 5.23(\mathrm{~s}, 2 \mathrm{H}), 4.18(\mathrm{t}, J=6.6 \mathrm{~Hz}, 2 \mathrm{H}), 1.94(\mathrm{t}, J=7.2 \mathrm{~Hz}, 2 \mathrm{H}), 1.82-1.77$ $(\mathrm{m}, 2 \mathrm{H}), 1.52-1.41(\mathrm{~m}, 4 \mathrm{H}), 1.36-1.23(\mathrm{~m}, 4 \mathrm{H}) .{ }^{13} \mathrm{C}-\mathrm{NMR}\left(150 \mathrm{MHz}, \mathrm{DMSO}-d_{6}\right) \delta 169.11,165.35,162.06$, $161.61,154.52,138.82,133.18,130.48,128.04,127.55,126.43,124.04,112.79,108.74,101.52,88.05,69.32$, $67.19,32.24,28.47,28.35,27.93,25.29,25.05$. HRMS (ESI) calcd for $\mathrm{C}_{24} \mathrm{H}_{26} \mathrm{CINO}_{6}[\mathrm{M}+\mathrm{H}]^{+} 460.1521$; found 460.1522. HPLC purity: $98.97 \%, \mathrm{t}_{\mathrm{R}}=9.096 \mathrm{~min}$.

N-Hydroxy-8-((7-((4-chlorobenzyl)oxy)-2-oxo-2H-chromen-4-yl)oxy)octanoic acid (14j). Yield: 31\%. ${ }^{1} \mathrm{H}-\mathrm{NMR}$ $\left(600 \mathrm{MHz}\right.$, DMSO- $\left.d_{6}\right) \delta 10.33$ (brs, $\left.1 \mathrm{H}\right), 8.65$ (brs, $\left.1 \mathrm{H}\right), 7.70(\mathrm{~d}, J=8.4 \mathrm{~Hz}, 1 \mathrm{H}), 7.51(\mathrm{~d}, J=8.4 \mathrm{~Hz}$, $2 \mathrm{H}), 7.47(\mathrm{~d}, J=8.4 \mathrm{~Hz}, 2 \mathrm{H}), 7.06-7.01(\mathrm{~m}, 2 \mathrm{H}), 5.73(\mathrm{~s}, 1 \mathrm{H}), 5.22(\mathrm{~s}, 2 \mathrm{H}), 4.18(\mathrm{t}, J=6.6 \mathrm{~Hz}, 2 \mathrm{H})$, $1.94(\mathrm{t}, J=7.2 \mathrm{~Hz}, 2 \mathrm{H}), 1.81-1.77(\mathrm{~m}, 2 \mathrm{H}), 1.52-1.41(\mathrm{~m}, 4 \mathrm{H}), 1.36-1.23(\mathrm{~m}, 4 \mathrm{H}) .{ }^{13} \mathrm{C}-\mathrm{NMR}(150 \mathrm{MHz}$, DMSO- $\left.d_{6}\right) \delta 169.10,165.35,162.06,161.67,154.52,135.29,132.71,129.76,128.54,124.00,112.81,108.68$, $101.51,88.02,69.31,69.01,32.23,28.47,28.35,27.93,25.29,25.05$. HRMS (ESI) calcd for $\mathrm{C}_{24} \mathrm{H}_{26} \mathrm{ClNO}_{6}$ $[\mathrm{M}+\mathrm{H}]^{+} 460.1521$; found 460.1518 . HPLC purity: $97.14 \%, \mathrm{t}_{\mathrm{R}}=6.715 \mathrm{~min}$.

N-Hydroxy-8-((7-((4-bromobenzyl)oxy)2-oxo-2H-chromen-4-yl)oxy)octanoic acid (14k). Yield: 32\%. ${ }^{1} \mathrm{H}-\mathrm{NMR}$ $\left(600 \mathrm{MHz}, \mathrm{DMSO}-d_{6}\right) \delta 10.33$ (brs, $\left.1 \mathrm{H}\right), 8.65(\mathrm{brs}, 1 \mathrm{H}), 7.70(\mathrm{~d}, J=8.4 \mathrm{~Hz}, 1 \mathrm{H}), 7.61(\mathrm{~d}, J=8.4 \mathrm{~Hz}, 2 \mathrm{H})$, $7.43(\mathrm{~d}, J=7.8 \mathrm{~Hz}, 2 \mathrm{H}), 7.06-7.01(\mathrm{~m}, 2 \mathrm{H}), 5.73(\mathrm{~s}, 1 \mathrm{H}), 5.20(\mathrm{~s}, 2 \mathrm{H}), 4.18(\mathrm{t}, J=6.0 \mathrm{~Hz}, 2 \mathrm{H}), 1.94(\mathrm{t}, J=$ $7.2 \mathrm{~Hz}, 2 \mathrm{H}), 1.81-1.77(\mathrm{~m}, 2 \mathrm{H}), 1.52-1.41(\mathrm{~m}, 4 \mathrm{H}), 1.36-1.23(\mathrm{~m}, 4 \mathrm{H}) .{ }^{13} \mathrm{C}-\mathrm{NMR}\left(150 \mathrm{MHz}\right.$, DMSO- $\left.d_{6}\right)$

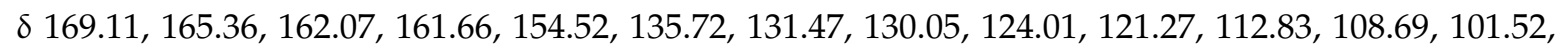
88.03, 69.31, 69.04, 32.24, 28.47, 28.34, 27.92, 25.29, 25.04. HRMS (ESI) calcd for $\mathrm{C}_{24} \mathrm{H}_{26} \mathrm{BrNO}_{6}[\mathrm{M}+\mathrm{H}]^{+}$ 504.1016; found 504.1018. HPLC purity: $96.29 \%, \mathrm{t}_{\mathrm{R}}=9.300 \mathrm{~min}$.

N-Hydroxy-8-((7-((4-trifluoromethyl)oxy))-2-oxo-2H-chromen-4-yl)oxy)octanoic acid (141). Yield: 31\%. ${ }^{1} \mathrm{H}-\mathrm{NMR}\left(600 \mathrm{MHz}, \mathrm{DMSO}-d_{6}\right) \delta 10.33$ (brs, $\left.1 \mathrm{H}\right), 8.66$ (brs, $\left.1 \mathrm{H}\right), 7.78(\mathrm{~d}, J=7.8 \mathrm{~Hz}, 2 \mathrm{H}), 7.71-7.69$ $(\mathrm{m}, 3 \mathrm{H}), 7.08-7.04(\mathrm{~m}, 2 \mathrm{H}), 5.73(\mathrm{~s}, 1 \mathrm{H}), 5.34(\mathrm{~s}, 2 \mathrm{H}), 4.17(\mathrm{t}, J=6.0 \mathrm{~Hz}, 2 \mathrm{H}), 1.94(\mathrm{t}, J=7.8 \mathrm{~Hz}, 2 \mathrm{H})$, 1.80-1.78 (m, 2H), 1.52-1.41 (m, 4H), 1.36-1.22 (m, 4H). ${ }^{13} \mathrm{C}-\mathrm{NMR}\left(150 \mathrm{MHz}\right.$, DMSO-d $\left.d_{6}\right) \delta 169.11,165.33$, $162.04,161.55,154.52,141.14,128.23$, 125.52, 125.44, 125.42, 125.39, 125.11, 124.07, 112.78, 108.80, 101.55, 88.07, 69.32, 68.92, 32.24, 28.47, 28.35, 27.93, 25.29, 25.05. HRMS (ESI) calcd for $\mathrm{C}_{24} \mathrm{H}_{26} \mathrm{~F}_{3} \mathrm{NO}_{6}[\mathrm{M}+\mathrm{H}]^{+}$ 494.1785; found 494.1784. HPLC purity: $95.43 \%, \mathrm{t}_{\mathrm{R}}=8.818 \mathrm{~min}$.

N-Hydroxy-8-((7-((2,6-difluorobenzyl)oxy)2-oxo-2H-chromen-4-yl)oxy)octanoic acid (14m). Yield: 29\%. ${ }^{1} \mathrm{H}-\mathrm{NMR}\left(600 \mathrm{MHz}, \mathrm{DMSO}-d_{6}\right) \delta 10.33$ (brs, $\left.1 \mathrm{H}\right), 8.65$ (brs, $\left.1 \mathrm{H}\right), 7.71(\mathrm{~d}, J=7.8 \mathrm{~Hz}, 1 \mathrm{H}), 7.58-7.53$ (m, $1 \mathrm{H}), 7.22-7.15(\mathrm{~m}, 3 \mathrm{H}), 7.03-7.01(\mathrm{~m}, \mathrm{H}), 5.75(\mathrm{~s}, 1 \mathrm{H}), 5.23(\mathrm{~s}, 2 \mathrm{H}), 4.18(\mathrm{t}, J=6.0 \mathrm{~Hz}, 2 \mathrm{H}), 1.94(\mathrm{t}, J=7.2$ $\mathrm{Hz}, 2 \mathrm{H}), 1.82-1.77(\mathrm{~m}, 2 \mathrm{H}), 1.52-1.42(\mathrm{~m}, 4 \mathrm{H}), 1.36-1.24(\mathrm{~m}, 4 \mathrm{H}) .{ }^{13} \mathrm{C}-\mathrm{NMR}\left(150 \mathrm{MHz}\right.$, DMSO- $\left.d_{6}\right) \delta$ 169.12, 165.33, 162.07, 162.01, 161.54, 160.40, 154.54, 132.13, 124.07, 112.58, 112.00, 111.83, 111.54, 108.94, $101.33,88.16,69.34,58.30,32.24,28.48,28.36,27.93,25.30,25.06$. HRMS (ESI) calcd for $\mathrm{C}_{24} \mathrm{H}_{25} \mathrm{~F}_{2} \mathrm{NO}_{6}$ $[\mathrm{M}+\mathrm{H}]^{+}$462.1723; found 462.1719. HPLC purity: $97.95 \%, \mathrm{t}_{\mathrm{R}}=8.157 \mathrm{~min}$.

N-Hydroxy-8-((7-((2,4-difluorobenzyl)oxy)2-oxo-2H-chromen-4-yl)oxy)octanoic acid (14n). Yield: 28\%. ${ }^{1} \mathrm{H}-\mathrm{NMR}\left(600 \mathrm{MHz}\right.$, DMSO- $\left.d_{6}\right) \delta 10.33$ (brs, $\left.1 \mathrm{H}\right), 8.65(\mathrm{brs}, 1 \mathrm{H}), 7.71-7.65(\mathrm{~m}, 2 \mathrm{H}), 7.35-7.31(\mathrm{~m}, 1 \mathrm{H})$, 
7.16-7.12 (m, 2H), 7.03-7.02 (m, H), $5.74(\mathrm{~s}, 1 \mathrm{H}), 5.21(\mathrm{~s}, 2 \mathrm{H}), 4.18(\mathrm{t}, J=6.0 \mathrm{~Hz}, 2 \mathrm{H}), 1.94(\mathrm{t}, J=7.2 \mathrm{~Hz}$, 2H), 1.82-1.77 (m, 2H) 1.52-1.42 (m, 4H), 1.36-1.24 (m, 4H). ${ }^{13} \mathrm{C}-\mathrm{NMR}\left(150 \mathrm{MHz}\right.$, DMSO- $\left.d_{6}\right) \delta 169.10$, $165.34,162.06,161.59,154.53,132.52,124.03,119.60,119.49,112.66,117.71,108.78,104.28,104.08,101.36$, 88.09, 69.32, 63.85, 32.23, 28.46, 28.34, 27.92, 25.29, 25.04. HRMS (ESI) calcd for $\mathrm{C}_{24} \mathrm{H}_{25} \mathrm{~F}_{2} \mathrm{NO}_{6}[\mathrm{M}+\mathrm{H}]^{+}$ 462.1723; found 462.1726. HPLC purity: $97.94 \%, \mathrm{t}_{\mathrm{R}}=7.569 \mathrm{~min}$.

N-Hydroxy-8-((7-((2-chloro-4-fluorobenzyl)oxy)2-oxo-2H-chromen-4-yl)oxy)octanoic acid (14o). Yield: 30\%. ${ }^{1} \mathrm{H}-\mathrm{NMR}\left(600 \mathrm{MHz}, \mathrm{DMSO}-d_{6}\right) \delta 10.32$ (brs, 1H), 8.65 (brs, 1H), 7.72-7.69 (m, 2H), 7.56-7.54 (m, H), 7.31-7.28 (m, H), 7.13-7.03 (m, 2H), $5.75(\mathrm{~s}, 1 \mathrm{H}), 5.24(\mathrm{~s}, 2 \mathrm{H}), 4.19(\mathrm{t}, J=6.6 \mathrm{~Hz}, 2 \mathrm{H}), 1.94(\mathrm{t}, J=7.2 \mathrm{~Hz}$, 2H), 1.82-1.78 (m, 2H), 1.52-1.42 (m, 4H), 1.37-1.25 (m, 4H). ${ }^{13} \mathrm{C}-\mathrm{NMR}\left(150 \mathrm{MHz}\right.$, DMSO-d $\left.d_{6}\right) \delta 169.10$, 165.34, 162.06, 161.64, 154.53, 132.47, 130.06, 124.06, 117.06, 116.89, 114.69, 114.55, 112.65, 108.85, 101.49, 88.10, 69.32, 67.08, 32.23, 28.46, 28.34, 27.92, 25.29, 25.04. HRMS (ESI) calcd for $\mathrm{C}_{24} \mathrm{H}_{25} \mathrm{~F}_{2} \mathrm{NO}_{6}[\mathrm{M}+\mathrm{H}]^{+}$ 478.1427; found 478.1432. HPLC purity: $95.38 \%, \mathrm{t}_{\mathrm{R}}=7.474 \mathrm{~min}$.

N-Hydroxy-8-((7-((2-methylbenzyl)oxy)-2-oxo-2H-chromen-4-yl)oxy)octanoic acid (14p). Yield: 29\%. ${ }^{1} \mathrm{H}-\mathrm{NMR}\left(600 \mathrm{MHz}, \mathrm{DMSO}-d_{6}\right) \delta 10.33$ (brs, $\left.1 \mathrm{H}\right), 8.66$ (brs, $\left.1 \mathrm{H}\right), 7.71$ (d, $\left.J=7.2 \mathrm{~Hz}, 1 \mathrm{H}\right), 7.43$ (d, $J=7.2 \mathrm{~Hz}, 1 \mathrm{H}), 7.27-7.20(\mathrm{~m}, 3 \mathrm{H}), 7.11-7.03(\mathrm{~m}, 2 \mathrm{H}), 5.73(\mathrm{~s}, 1 \mathrm{H}), 5.20(\mathrm{~s}, 2 \mathrm{H}), 4.18(\mathrm{t}, J=6.6 \mathrm{~Hz}, 2 \mathrm{H}), 2.33$ $(\mathrm{s}, 3 \mathrm{H}), 1.94(\mathrm{t}, J=7.2 \mathrm{~Hz}, 2 \mathrm{H}), 1.82-1.77(\mathrm{~m}, 2 \mathrm{H}), 1.52-1.41(\mathrm{~m}, 4 \mathrm{H}), 1.36-1.24(\mathrm{~m}, 4 \mathrm{H}) .{ }^{13} \mathrm{C}-\mathrm{NMR}(150$ MHz, DMSO- $\left.d_{6}\right) \delta 169.12,165.41,162.11,162.01,154.58,136.80,134.16,130.23,128.74,128.36,125.86$, $123.97,112.78,108.59,101.44,87.95,69.30,68.66,32.24,28.48,28.35,27.93,25.30,25.05,18.48$. HRMS (ESI) calcd for $\mathrm{C}_{25} \mathrm{H}_{29} \mathrm{NO}_{6}[\mathrm{M}+\mathrm{H}]^{+} 440.2068$; found 440.2072. HPLC purity: $93.79 \%, \mathrm{t}_{\mathrm{R}}=6.635 \mathrm{~min}$.

N-Hydroxy-8-((7-((3-methylbenzyl)oxy)-2-oxo-2H-chromen-4-yl)oxy)octanoic acid (14q). Yield: 31\%. ${ }^{1} \mathrm{H}-\mathrm{NMR}\left(600 \mathrm{MHz}, \mathrm{CD}_{3} \mathrm{OD}\right) \delta 7.73(\mathrm{~d}, J=8.4 \mathrm{~Hz}, 1 \mathrm{H}), 7.27-7.22(\mathrm{~m}, 3 \mathrm{H}), 7.15(\mathrm{~d}, J=7.2 \mathrm{~Hz}$, $1 \mathrm{H}), 6.99-6.92(\mathrm{~m}, 2 \mathrm{H}), 5.63(\mathrm{~s}, 1 \mathrm{H}), 5.12(\mathrm{~s}, 2 \mathrm{H}), 4.17(\mathrm{~s}, 2 \mathrm{H}), 2.35(\mathrm{~s}, 3 \mathrm{H}), 2.10(\mathrm{t}, J=7.2 \mathrm{~Hz}, 2 \mathrm{H}), 1.89(\mathrm{~s}$, 2H), 1.65-1.53 (m, 4H), 1.43-1.38 (m, 4H). ${ }^{13} \mathrm{C}-\mathrm{NMR}\left(150 \mathrm{MHz}, \mathrm{CD}_{3} \mathrm{OD}\right) \delta 172.97,168.23,165.97,164.10$, $156.27,139.47,137.61,129.88,129.54,129.33,125.81,125.27,114.24,110.25,102.50,88.40,71.61,70.83$, $33.72,29.99,29.97,29.53,26.88,26.64,21.43$. HRMS (ESI) calcd for $\mathrm{C}_{25} \mathrm{H}_{29} \mathrm{NO}_{6}[\mathrm{M}+\mathrm{H}]^{+} 440.2068$; found 440.2070 . HPLC purity: $97.60 \%, \mathrm{t}_{\mathrm{R}}=6.704 \mathrm{~min}$.

N-Hydroxy-8-((7-((4-methylbenzyl)oxy)2-oxo-2H-chromen-4-yl)oxy)octanoic acid (14r). Yield: 33\%. ${ }^{1} \mathrm{H}-\mathrm{NMR}$ $(600 \mathrm{MHz}$, DMSO-d 6 ) $\delta 10.33$ (brs, $1 \mathrm{H}), 8.65$ (brs, $1 \mathrm{H}), 7.68(\mathrm{~d}, J=8.4 \mathrm{~Hz}, 1 \mathrm{H}), 7.36(\mathrm{~d}, J=7.8 \mathrm{~Hz}, 2 \mathrm{H})$, $7.21(\mathrm{~d}, J=7.8 \mathrm{~Hz}, 2 \mathrm{H}), 7.04-6.99(\mathrm{~m}, 2 \mathrm{H}), 5.72(\mathrm{~s}, 1 \mathrm{H}), 5.16(\mathrm{~s}, 2 \mathrm{H}), 4.17(\mathrm{t}, J=6.0 \mathrm{~Hz}, 2 \mathrm{H}), 2.31(\mathrm{~s}$, $3 \mathrm{H}), 1.94(\mathrm{t}, J=7.2 \mathrm{~Hz}, 2 \mathrm{H}), 1.81-1.77(\mathrm{~m}, 2 \mathrm{H}), 1.52-1.41(\mathrm{~m}, 4 \mathrm{H}), 1.36-1.24(\mathrm{~m}, 4 \mathrm{H}) .{ }^{13} \mathrm{C}-\mathrm{NMR}(150$ MHz, DMSO- $\left.d_{6}\right) \delta 169.09,165.38,162.08,161.90,154.53,137.41,133.17,129.06,128.04,123.92,112.85$, $108.49,101.44,87.92,69.81,69.28,32.23,28.46,28.34,27.92,25.29,25.04,20.79$. HRMS (ESI) calcd for $\mathrm{C}_{25} \mathrm{H}_{29} \mathrm{NO}_{6}[\mathrm{M}+\mathrm{H}]^{+} 440.2068$; found 440.2072. HPLC purity: $97.62 \%, \mathrm{t}_{\mathrm{R}}=9.009 \mathrm{~min}$.

N-Hydroxy-8-((7-((2,6-dimethylbenzyl)oxy)-2-oxo-2H-chromen-4-yl)oxy)octanoic acid (14s). Yield: 29\%. ${ }^{1} \mathrm{H}-\mathrm{NMR}\left(600 \mathrm{MHz}, \mathrm{CD}_{3} \mathrm{OD}\right) \delta 7.79(\mathrm{~d}, J=8.4 \mathrm{~Hz}, 1 \mathrm{H}), 7.15(\mathrm{dd}, J=7.2 \mathrm{~Hz}, 7.2 \mathrm{~Hz}, 1 \mathrm{H}), 7.08-7.06$ $(\mathrm{m}, 3 \mathrm{H}), 7.02-7.00(\mathrm{~m}, \mathrm{H}), 5.67(\mathrm{~s}, 1 \mathrm{H}), 5.19(\mathrm{~s}, 2 \mathrm{H}), 4.21(\mathrm{t}, J=6.0 \mathrm{~Hz}, 2 \mathrm{H}), 2.37(\mathrm{~s}, 6 \mathrm{H}), 2.10(\mathrm{t}, J=$ $7.2 \mathrm{~Hz}, 2 \mathrm{H}), 1.94-1.89(\mathrm{~m}, 2 \mathrm{H}), 1.67-1.53(\mathrm{~m}, 4 \mathrm{H}), 1.47-1.37(\mathrm{~m}, 4 \mathrm{H}) .{ }^{13} \mathrm{C}-\mathrm{NMR}\left(150 \mathrm{MHz}, \mathrm{CD}_{3} \mathrm{OD}\right) \delta$ 172.97, 168.32, 166.04, 164.64, 156.43, 139.33, 133.45, 129.83, 129.30, 125.35, 114.10, 110.31, 102.15, 88.41, $70.86,66.58,32.72,30.00,29.98,29.55,26.90,26.65,19.60$. HRMS (ESI) calcd for $\mathrm{C}_{26} \mathrm{H}_{31} \mathrm{NO}_{6}[\mathrm{M}+\mathrm{H}]^{+}$ 454.2224; found 454.2221. HPLC purity: $97.43 \%, \mathrm{t}_{\mathrm{R}}=7.566 \mathrm{~min}$.

Spectra of ${ }^{1} \mathrm{H}$ and ${ }^{13} \mathrm{C}-\mathrm{NMR}$ and HR MS and HPLC for new compounds 13a-g and 14a-s can be found in Supplementary Materials.

\subsection{HDAC1 Inhibitory Assay}

The enzyme inhibitory assay was conducted by Shanghai ChemPartner Corporation (Shanghai, China). Briefly, HDAC1 enzyme solution was incubated with SAHA or target compounds at different concentrations in the presence of HDAC substrate (Boc-Lys(Ac)-AMC) at $37^{\circ} \mathrm{C}$ for $60 \mathrm{~min}$. Then the 
lysine developer was added to terminate the reaction, and the samples were further incubated at $37^{\circ} \mathrm{C}$ for $30 \mathrm{~min}$. The data were recorded on an ELISA plate reader at $405 \mathrm{~nm}$. Three independent experiments with triplicate were carried out.

\subsection{Cell Culture and Reagents}

The cells used in the experiment included two human breast cancer cell lines (MCF-7, MDA-MB-231) and two human lung adenocarcinoma cell lines (H157, A549). Cancer cells $\left(6 \times 10^{3}\right.$ per well) were inoculated into 96-well plates. The treatment was carried out for $48 \mathrm{~h}$, followed by SRB staining, and the absorption value was measured at $540 \mathrm{~nm}$ by a microplate reader. SAHA was used as a positive control, and the independent experiment was performed three times.

\subsection{Colony Formation Assay}

Six-well plates were inoculated with MDA-MB-231 cells (800/well). The plate was continuously cultured for four days until the cells became agglomerated, and then treated with SAHA and 13a, 13c, change the dosing medium every $24 \mathrm{~h}$. One week after the addition of the drugs, the medium was removed. The cells were then washed three times with PBS and fixed in methanol for $5 \mathrm{~min}$. The cells were lastly stained with $1 \%$ crystal violet (Beyotime) for 15 min and washed with PBS. Images were collected using a scanning apparatus (Canon, Tokyo, Japan).

\subsection{Western Blot Analysis}

Briefly, MDA-MB-231 cells were lysed in lysis buffer (50 mM Tris- $\mathrm{HCl} \mathrm{pH}$ 8.0, $5 \mathrm{mM}$ EDTA, $100 \mathrm{mM} \mathrm{NaCl}, 0.5 \% \mathrm{NP}-40,1 \mathrm{mM}$ PMSF) and then centrifuged for $10 \mathrm{~min}$ at 12,000 $\mathrm{r}$, and the insoluble debris was discarded. Cell lysates were further analyzed with SDS-PAGE and western blotting with indicated antibodies. After treatment with 13a and 13c for indicated times, cells were harvested with RIPA buffer (150 mM sodium chloride, $1 \%$ Triton X-100, 0.5\% sodium deoxycholate, $0.1 \%$ SDS, $50 \mathrm{mM}$ Tris and cocktails of protease and phosphatase inhibitors) for $10 \mathrm{~min}$ at room temperature and boiled for another $10 \mathrm{~min}$. Equal amounts of total proteins $(35 \mu \mathrm{g})$ underwent 15\% SDS-PAGE and were electroblotted onto the polyvinylidene difluoride (PVDF) membrane. The membrane was blocked with 5\% $(w / v)$ fat-free dry milk in PBS-Tween 20 (PBST; 0.05\%) for $1 \mathrm{~h}$ and incubated with primary antibody (1:1000 in PBST) at $4{ }^{\circ} \mathrm{C}$ overnight. After three washings in PBST, the PVDF membrane was incubated with appropriate horseradish peroxidase-conjugated secondary antibodies $(1: 20,000)$ for 1 $\mathrm{h}$ at room temperature. The immunoreactive bands were developed with the ECL western blotting system. $\beta$-Actin was used as loading control. The relative quantity of proteins was analyzed via the Image J software (NIH, Bethesda, MD, USA).

\subsection{Anti-Migration Assay}

MDA-MB-231 cells were seeded in a six-well plate to form a monolayer cell tile state. A $200 \mu \mathrm{L}$ pipette tip was used to create a linear wound. The wound was washed with PBS to remove damaged cells and then recorded under a microscope. Compounds 13a, 13c and SAHA were then added, and the wells were further photographed at 24 and $48 \mathrm{~h}$, respectively. Results were expressed as the percent of wound healing that is, the distance migrated at $0 \mathrm{~h}$ minus the distance migrated at 24 or $48 \mathrm{~h}$ relative to the distance migrated at $0 \mathrm{~h}$.

\subsection{Cell Cycle Arrest Analysis and Apoptosis Analysis}

Briefly, cell cycle analysis was carried out by estimating DNA contents with flow cytometry at 488 $\mathrm{nm}$. MDA-MB-231 cells $\left(4 \times 10^{4}\right)$ were incubated in a small dish for $12 \mathrm{~h}$ and then medicated. After $24 \mathrm{~h}$ of cell cycle treatment, the cells were washed three times with PBS, and the cell suspension was collected, centrifuged again, and then added to an ethanol fixative $(70 \%)$ and placed in a refrigerator 
for overnight storage. After washing, the dye was added and stained with PI containing RNaseA solution for $30 \mathrm{~min}$ at $37^{\circ} \mathrm{C}$, and then analyzed by FACS.

Briefly, cell apoptosis analysis was measured by annexin V FITC/PI assay using Annexin v-PE/7-AAD Apoptosis Detection kit (BD). MDA-MB-231 cells $\left(2 \times 10^{5}\right)$ were incubated in a six-well plate for $12 \mathrm{~h}$ and then medicated. After $48 \mathrm{~h}$, the drug-treated cells were washed three times with PBS; the cell suspension was collected and centrifuged; and the supernatant was removed. Finally, the corresponding buffer solution $(500 \mu \mathrm{L})$ and the dye $(5 \mu \mathrm{L})$ were added to each sample, incubated at room temperature for 15-20 min and then detected by flow cytometer at $488 \mathrm{~nm}$.

\subsection{Molecular Docking Studies}

Molecular docking studies were carried out with Autodock-4.27. For the docking calculations HDAC1 crystal structure (PDB code: 4BKX) was retrieved from the Protein Data Bank (www.pdb.org). For protein preparation, all the water molecules were removed from HDAC1, and Gasteiger partial charges were assigned to the selected compound and enzyme atoms. The docking results were analyzed with the programs AutoDockTools (Olson, CA, USA), 27 DOCKRES and VMD.

\section{Conclusions}

We designed and synthesized a new series of coumarin-based hydroxamate HDACis and evaluated their biological activities in a series of in vitro assays. Most compounds showed excellent HDAC1 inhibitory activities and also displayed significant growth inhibition against different human cancer cells. Among them, compounds $\mathbf{1 3 a}$ and $\mathbf{1 3} \mathrm{c}$ were two to three times more active than SAHA, and further experimental investigations were conducted. Immunoblot analysis revealed that 13a and 13c dose-dependently increased the acetylation of histone $\mathrm{H} 3$ and $\mathrm{H} 4$, confirming their HDAC1 inhibitory effects. Furthermore, cell migration and colony formation assays showed that the two compounds displayed anti-metastatic and anti-proliferative activities. Moreover, 13a and 13c arrested MDA-MB-231 cells at G2/M phase and induced cell apoptosis. Finally, a molecular modeling study was also performed to assess the potential binding ability of 13c with HDAC1. Together, the present work afforded new HDACis that could be further investigated as promising anticancer candidates.

Supplementary Materials: The following are available online. Raw spectroscopic data including HPLC analyses, HRMS (ESI), and NMR $\left({ }^{1} \mathrm{H},{ }^{13} \mathrm{C}\right)$ spectra for new compounds $13 \mathbf{a}-\mathbf{g}$ and $\mathbf{1 4 a}-\mathbf{s}$.

Author Contributions: H.Z. and F.Y. designed and guided the project; N.Z. and Y.Q. conducted the chemical synthesis; N.Z., L.H. and D.G. performed the biological experiments; N.Z. prepared the manuscript and F.Y. and H.Z. revised and edited it. All authors have read and agreed to the published version of the manuscript.

Funding: We acknowledge the financial support from the Natural Science Foundation of China (No. 81703360), Shandong Provincial Key Research Project (2019GSF108178), the Natural Science Foundation of Shandong Province (No. JQ2017021), Shandong Excellent Young Scientist Award Fund (BS2014SW031), the Young Taishan Scholars Program (tsqn20161037), and the Shandong Talents Team Cultivation Plan of University Preponderant Discipline (No. 10027).

Conflicts of Interest: The authors declare no conflict of interest.

\section{References}

1. Nepali, K.; Sharma, S.; Sharma, M.; Bedi, P.M.S.; Dhar, K.L. Rational approaches, design strategies, structure activity relationship and mechanistic insights for anticancer hybrids. Eur. J. Med. Chem. 2014, 77, $422-487$. [CrossRef]

2. Sangwan, R.; Rajan, R.; Mandal, P.K. HDAC as onco target: Reviewing the synthetic approaches with SAR study of their inhibitors. Eur. J. Med. Chem. 2018, 158, 620-706. [CrossRef]

3. Marks, P.; Rifkind, R.A.; Richon, V.M.; Breslow, R.; Miller, T.; Kelly, W.K. Histone deacetylases and cancer: Causes and therapies. Nat. Rev. Cancer 2001, 1, 194-202. [CrossRef]

4. Ruijter, A.J.D.; Gennip, A.H.V.; Caron, H.N.; Kemp, S.; Kuilenburg, A.B.V. Histone deacetylases (HDACs): Characterization of the classical HDAC family. Biochem. J. 2003, 370, 737-749. [CrossRef] [PubMed] 
5. Monneret, C. Histone deacetylase inhibitors. Eur. J. Med. Chem. 2005, 40, 1-13. [CrossRef] [PubMed]

6. Bolden, J.E.; Peart, M.J.; Johnstone, R.W. Anticancer activities of histone deacetylase inhibitors. Nat. Rev. Drug Discov. 2006, 5, 769-784. [CrossRef] [PubMed]

7. Lee, H.Y.; Tsai, A.C.; Chen, M.C.; Shen, P.J.; Cheng, Y.C.; Kuo, C.C.; Pan, S.L.; Liu, Y.M.; Liu, J.F.; Yeh, T.K.; et al. Azaindolylsulfonamides, with a more selective inhibitory effect on histone deacetylase 6 activity, exhibit antitumor activity in colorectal cancer HCT116 cells. J. Med. Chem. 2014, 57, 4009-4022. [CrossRef] [PubMed]

8. Vreese, R.D.; Depetter, Y.; Verhaeghe, T.; Desmet, T.; Benoy, V.; Haeck, W.; Boschc, L.V.D.; D’hooghe, M. Synthesis and SAR assessment of novel Tubathian analogs in the pursuit of potent and selective HDAC6 inhibitors. Org. Biomol. Chem. 2016, 14, 2537-2549. [CrossRef] [PubMed]

9. Ojha, R.; Huang, H.L.; HuangFu, W.C.; Wu, Y.W.; Nepali, K.; Lai, M.J.; Su, C.J.; Sung, T.E.; Chen, Y.L.; Pan, S.L.; et al. 1-Aroylindoline-hydroxamic acids as anticancer agents, inhibitors of HSP90 and HDAC. Eur. J. Med. Chem. 2018, 150, 667-677. [CrossRef]

10. Abdizadeh, T.; Kalani, M.R.; Abnous, K.; Tayarani-Najaran, Z.; Khashyarmanesh, B.Z.; Abdizadeh, R.; Ghodsi, R.; Hadizadeh, F. Design, synthesis and biological evaluation of novel coumarin-based benzamides as potent histone deacetylase inhibitors and anticancer agents. Eur. J. Med. Chem. 2017, 132, 42-62. [CrossRef]

11. Bertrand, P. Inside HDAC with HDAC inhibitors. Eur. J. Med. Chem. 2010, 45, 2095-2116. [CrossRef] [PubMed]

12. Chen, X.; Zhao, S.; Li, H.M.; Wang, X.; Geng, A.; Cui, H.; Lu, T.; Chen, Y.D.; Zhu, Y. Design, synthesis and biological evaluation of novel isoindolinone derivatives as potent histone deacetylase inhibitors. Eur. J. Med. Chem. 2019, 168, 110-122. [CrossRef] [PubMed]

13. Dietz, K.C.; Casaccia, P. HDAC inhibitors and neurodegeneration: At the edge between protection and damage. Pharmacol. Res. 2010, 62, 11-17. [CrossRef] [PubMed]

14. Cheng, C.H.; Yun, F.; He, J.; Ullah, S.; Yuan, Q.P. Design, synthesis and biological evaluation of novel thioquinazolinone-based 2-aminobenzamide derivatives as potent histone deacetylase (HDAC) inhibitors. Eur. J. Med. Chem. 2019, 173, 185-202. [CrossRef]

15. Gao, L.; Cueto, M.A.; Asselbergs, F.; Atadja, P. Cloning and functional characterization of HDAC11, a novel member of the human histone deacetylase family. J. Biol. Chem. 2002, 277, 25748-25755. [CrossRef]

16. Bottomley, M.J.; Lo Surdo, P.; Di Giovine, P.; Cirillo, A.; Scarpelli, R.; Ferrigno, F.; Jones, P.; Neddermann, P.; De Francesco, R.; Steinkuhler, C.; et al. Structural and functional analysis of the human HDAC4 catalytic domain reveals a regulatory structural zinc-binding domain. J. Biol. Chem. 2008, 283, 26694-26704. [CrossRef]

17. Haigis, M.C.; Guarente, L.P. Mammalian sirtuins-emerging roles in physiology, aging, and calorie restriction. Genes Dev. 2006, 20, 2913-2921. [CrossRef]

18. Liu, T.; Liu, P.Y.; Marshall, G.M. The critical role of the class III histone deacetylase SIRT1 in cancer. Cancer Res. 2009, 69, 1702-1705. [CrossRef]

19. Choo, Q.Y.; Paul, C.H.; Tanaka, Y.; Lin, H.S. Histone deacetylase inhibitors MS-275 and SAHA induced growth arrest and suppressed lipopolysaccharide-stimulated NF-kappaB P65 nuclear accumulation in human rheumatoid arthritis synovial fibroblastic E11 cells. Rheumatology 2010, 49, 1447-1460. [CrossRef]

20. Lee, H.Z.; Kwitkowski, V.E.; Del Valle, P.L.; Ricci, M.S.; Saber, H.; Habtemariam, B.A.; Bullock, J.; Bloomquist, E.; Shen, Y.L.; Chen, X.H. FDA approval: Belinostat for the treatment of patients with relapsed or refractory peripheral T-cell lymphoma. Clin. Cancer Res. 2015, 21, 2666-2670. [CrossRef]

21. Garnock-Jones, K.P. Panobinostat: First global approval. Drugs 2015, 25, 695-704. [CrossRef]

22. Furumai, R.; Matsuyama, A.; Kobashi, N.; Lee, K.H.; Nishiyama, M.; Nakajima, H.; Tanaka, A.; Komatsu, Y.; Nishino, N.; Yoshida, M. FK228 (depsipeptide) as a natural prodrug that inhibits classI histone deacetylases. Cancer Res. 2002, 62, 4916-4921.

23. Moradei, O.; Vaisburg, A.; Martell, R.E. Histone deacetylase inhibitors in cancer therapy: New compounds and clinical update of benzamide-type agents. Curr. Top. Med. Chem. 2008, 8, 841-858. [CrossRef]

24. Taddei, M.; Cini, E.; Giannotti, L.; Giannini, G.; Battistuzzi, G.; Vignola, D.; Vesci, L.; Cabri, W. Lactam based 7-amino suberoylamide hydroxamic acids as potent HDAC inhibitors. Bioorganic Med. Chem. 2014, 24, 61-64. [CrossRef]

25. Huang, M.L.; Zhang, J.; Yan, C.J.; Li, X.H.; Zhang, J.L.; Ling, R. Small molecule HDAC inhibitors: Promising agents for breast cancer treatment. Bioorganic Chem. 2019, 91, 103184. [CrossRef] [PubMed] 
26. Jin, P.; Chen, X. Current status of epigenetics and anticancer drug discovery. Anti-Cancer Agents Med. Chem. 2016, 16, 699-712. [CrossRef]

27. Manal, M.; Chandrasekar, M.J.N.; Priya, J.G.; Nanjan, M.J. Inhibitors of histone deacetylase as antitumor agents: A critical review. Bioorganic Chem. 2016, 67, 18-42. [CrossRef] [PubMed]

28. Zhan, P.; Wang, X.; Liu, X.; Suzuki, T. Medicinal chemistry insights into novel HDAC inhibitors: An updated patent review (2012-2016). Recent pat. Anti-Cancer Drug Discov. 2017, 12, 16-34. [CrossRef] [PubMed]

29. Bansal, Y.; Sethi, P.; Bansal, G. Coumarin: A potential nucleus for anti-inflammatory molecules. Med. Chem. Res. 2013, 22, 3049-3060. [CrossRef]

30. Amin, K.M.; Awadalla, F.M.; Eissa, A.A.M.; Abou-Seri, S.M.; Hassan, G.S. Design, synthesis and vasorelaxant evaluation of novel coumarin-pyrimidine hybrids. Bioorganic Med. Chem. 2011, 19, 6087-6097. [CrossRef] [PubMed]

31. Basanagouda, M.; Jambagi, V.B.; Barigidad, N.N.; Laxmeshwar, S.S.; Devaru, V.; Narayana, C. Synthesis, structure-activity relationship of iodinated-4-aryloxymethyl-coumarins as potential anti-cancer and anti-mycobacterial agents. Eur. J. Med. Chem. 2014, 74, 225-233. [CrossRef] [PubMed]

32. Riveiro, M.E.; Moglioni, A.; Vazquez, R.; Gomez, N.; Facorro, G.; Piehl, L.; De Celis, E.R.; Shayo, C.; Davio, C. Structural insights into hydroxycoumarin-induced apoptosis in U-937 cells. Bioorganic Med. Chem. 2008, 16, 2665-2675. [CrossRef] [PubMed]

33. Yang, F.F.; Zhao, N.; Song, J.L.; Zhu, K.K.; Jiang, C.S.; Shan, P.P.; Zhang, H. Design, synthesis and biological evaluation of novel coumarin-based hydroxamate derivatives as histone deacetylase (hdac) inhibitors with antitumor activities. Molecules 2019, 24, 2569. [CrossRef] [PubMed]

34. Ge, D.; Han, L.N.; Yang, F.F.; Zhao, N.; Yang, Y.; Zhang, H.; Chen, Y.H. Development of hydroxamate-based histone deacetylase inhibitors of bis-substituted aromatic amides with antitumor activities. MedChemComm 2019, 10, 1828-1837. [CrossRef]

Sample Availability: Samples of compounds 13a-g and 14a-s are available from the authors.

(C) 2020 by the authors. Licensee MDPI, Basel, Switzerland. This article is an open access article distributed under the terms and conditions of the Creative Commons Attribution (CC BY) license (http://creativecommons.org/licenses/by/4.0/). 